\title{
Der Einfluß der jacobinistischen und sozialdemokratischen Tradition auf das leninistische Organisationskonzept
}

\author{
Bernd Rabehl, Willfried Spohn, Ulf Wolter
}

\section{Die politische Motivation einer Kritik am ,Marxismus-Leninismus"}

Unsere Untersuchung verfolgt das Ziel, den wissenschaftlich materialistischen Beweis anzutreten, daß im Leninschen Denken die Radition des Jacobinismus der russischen Intelligentsija und der sozialdemokratischen Ideologie der II. Internationale nachgewiesen werden kann. Diese Behauptung wurde von bürgerlicher und sozialdemokratischer Seite schon oft aufgeworfen und sie verschwieg dabei die ideologischen Absichten nicht, nachzuweisen, daß der „Leninismus“ auf die westeuropäische Arbeiterbewegung ,aufgepfropft" sei und daß die liberale oder sozialdemokratische „Weltanschauung" als adäquater Ausdruck westeuropäischer Verhältnisse anzusehen ist. Trotzdem kann diese Problemstellung nicht ignoriert werden.

Nach den ersten Anstrengungen der Organisierung und dem Erstellen von politischen Leitsätzen, die die verschiedenen Fraktionen der ,linken“" Intellektuellenopposition in Westdeutschland bzw. Westberlin aufsichnahmen, erfolgt nun nicht zufällig die kritische Reaktion. Die Zersetzung dieser Opposition erschien in vielfältiger Gestalt. Die Einen wurden von den traditionellen Reformparteien aufgesogen und in die aktuelle Realpolitik integriert. Unter dem Vorzeichen der Konjunktur schienen die Weichen auf Reformen gestellt, die die Ziele dieser außerparlamentarischen Opposition erfüllen konnten. Die Anderen verschrieben sich einem überbrachten „Marxismus-Leninismus", der die Rolle und Funktion einer revolutionären Intelligenz zu formulieren schien, sich über eine Partei von Berufssrevolutionären mit der Arbeiterbewegung zu verschmelzen. Die Resonanz, die die radikaldemokratischen Forderungen der Intellektuellenopposition 1967/68 bei Teilen des Mittelstandes, der Kleinbürger, aber auch bei den Arbeitern gefunden hatte, sowie die Aktionsformen des Protestes gegen die alte Ordinarienuniversität, gegen die Verabschiedung der Notstandsgesetze oder gegen den amerikanischen Krieg in Vietnam, ließ bei den Vertretern und Akteuren dieser Opposition die Illusion aufkommen, daß sie durch die Ereignisse aufgerufen seien, den politischen und organisatorischen Anfang für eine neue Politik zu setzen, der man freimütig das Prädikat ,revolutionär " verlieh. Die bestehenden Reformparteien, die SPD, bereits voll in das kapitalistische System integriert und mit Regierungsverantwortung versehen sowie die DKP, staatspolitisch verkleinert und selbst isoliert zu einer winzigen Minorität, die durch die Reproduktion alter sozialdemokratischer Phrasen sich vormachte, eine linke Arbeiterpartei zu werden, wurden zum ,alten Eisen ${ }^{66}$ geworfen und als Bestandteile der bürgerlichen Ordnung diskreditiert. Statt nun die reale Situation des politischen Kampfes in Deutschland und dessen Verbindung zu den westeuropäischen Klassenkämpfen zu bedenken, um die Maßstäbe für die Politik und für Orga- 
nisationsformen zu finden, die Mittel der Massenmobilisierung im Bereich des Überbaus und in Zukunft im Bereich der Produktion werden konnten, wurde umgekehrt mit Hilfe des „Marxismus-Leninismus " eine Flucht vor der Realität angetreten. Die politische Isolierung einer politisierten Intelligenz von der Klassenkampfbewegung der Arbeiter, die über Jahre hinweg diese Opposition geprägt, ja sogar erst ermöglicht hatte, wurde kurzerhand ignoriert, dafür aber die Existenzprobleme dieser Intelligenz in den Vordergrund gerückt. Die Dequalifizierung, Proletarisierung, der Leistungsdruck, die drohende Arbeitslosigkeit für Akademiker, die Fehlplanungen in der Bildungspolitik usw. usf., Tatsachen für die Hochschulsituation, die primär diese Opposition produziert hatten, wurden zur revolutionären Bereitschaft, zum berufsrevolutionären Existenzialismus verabsolutiert. Diese Trennung von der Arbeiterbewegung, selbst noch Ausdruck der Arbeitsteilung im kapitalistischen System, wurde durch die Optik des „Marxismus-Leninismus“ verfremdet und durch den Parteiaufbau vollkommen verdrängt. Durch banale Analogien zur russischen, chinesischen Revolution oder zur KPD-Politik der zwanziger Jahre wurde diese Selbsttäuschung vollführt. Da psychologische Erwartungshaltungen im Vordergrund standen, konnte dieses gruppendynamische Experiment gelingen, das durch keinerlei geistige Reflektionen aufgehalten werden konnte.

Der Formierung der reaktionären Kräfte in Justiz, Polizei, im Militär, in den Kultusbürokratien, im Wirtschaftsapparat des Staates, sowie bei Parteien und Verbänden, vor allem beim Bund deutscher Industrieller und bei der CDU/CSU, steht in der Gegenwart eine hoffnungslos zersplitterte Linke und eine demoralisierte Arbeiterklasse gegenüber. Der Anfang einer ,"neuen ${ }^{6}$ Politik, der 1968/69 von verschiedener Seite postuliert wurde, stellt sich nun erst einmal als ein Ende „neuer" Ansätze der Politikformen heraus.

Während in Italien und Frankreich, aber auch in England, Spanien, Portugal und Griechenland die legalen und illegalen Parteien und Organisationen der Arbeiterklasse immer bestimmter die vorherrschende Politik der Monopolbourgeoisie und ihrer Parteien unter Druck setzen und sich unter den Bedingungen einer sich verschärfenden Krise, die in wachsender Schnelligkeit die reaktionären Kräfte und ihre Zwischenhändler verbraucht, sich vorbereiten, mit den linksbürgerlichen Parteien zu einem Bündnis zu kommen, um in die Regierung im Interesse der Arbeiter, Bauern und Kleinbürger einzusteigen, während gleichzeitig einzelne Aktionsformen der Arbeiter über eine derartige Politik hinausgehen und Keime setzen für eine revolutionäre Umwälzung der Gesellschaft, scheinen im westlichen Deutschland unter den Drohungen der Massenarbeitslosigkeit die ökonomischen Kämpfe der Arbeiter abzuflauen und politische Zielsetzungen sich erst gar nicht durchzusetzen. Die Klassenkampfbewegung der Arbeiter ist seit 1968 über kümmerliche Ansätze nicht hinausgekommen. Die sozialdemokratischen Illusionen konnten in der Hochkonjunktur nicht zerstört werden und so ist es bei den Anzeichen der Krise nicht verwunderlich, daß auch in dieser Klasse eine Rechtsorientierung einsetzt, die bei den besitzenden Klassen in einer Angstreaktion sofort aufkam und die jetzt die Sozialdemokratie zum Bestandteil der Ordnungspartei werden läßt.

Verflogen sind alle Träume der Reform. Es ist für die nächsten Jahre nicht zu 
erwarten, daß in dieser Situation eine Wende eintritt. Der westdeutsche Kapitalismus kann sich innerhalb der EWG und der NATO als die entscheidende ökonomische und politische Macht anbieten, den kapitalistischen Klassen jegliche Hilfe zukommen zu lassen. Eine soziale Revolution in irgendeiner west- oder südeuropäischen Gesellschaft, ohne daß sie in den anderen Ländern Unterstützung findet und ohne den westdeutschen Kapitalismus und die USA zu neutralisieren, wäre ein Sturm im Wasserglas.

In diesem politischen Kontext gewinnt die Kritik am „Marxismus-Leninismus $^{66}$ die Funktion, eine politische Kritik einzuleiten, um überhaupt wieder zu einer illusionslosen Politik vorzustoßen, oder um zumindest eine sozialistische Position für Deutschland zu formulieren. Der erste Schritt war der, nachzuweisen, daß die Lenin'sche Marxrezeption selbst Produkt bestimmter politischer Verhältnisse war, weshalb bestimmte Fehler und unrichtige Verallgemeinerungen in sein Denken eingingen, umgekehrt aber konnte auch durch den Druck der Verhältnisse an richtige Fragestellungen der Marx'schen Emanzipationstheorie angeschlossen werden. Im zweiten Schritt, der in diesem Aufsatz gemacht wird, soll eingegangen werden auf das Lenin'sche Politik- und Organisationsverständnis. Hier soll hervorgehoben werden, daß diese Konzeption konkret die russische Situation widerspiegelte, die in keiner Weise auf Westeuropa übertragen werden konnte. Eine derartige Analogie oder Projektion muß zu Fehlschlüssen und Niederlagen führen.

Die Lenin'sche Vorstellung über politische Taktik und Organisation der Arbeiterbewegung in Rußland variierte die Konzeption der Intelligentsija mit sozialdemokratischen Bestimmungen von Wissenschaft, Politik und Partei. In dieser Hinsicht blieb das Lenin'sche Denken vorrevolutionär, in dem vor allem die Reflektion sozialemanzipatorischer Aktionsformen der Arbeiter im Rahmen einer politischen Revolution, die die Bourgeoisie, die Großgrundbesitzer und das ausländische Kapital in Rußland von der Macht verdrängte, vermißt werden muß. In der realpolitischen Verflachung der Resultate des Lenin'schen Denkens, wie sie der in den zwanziger Jahren entstehende „Marxismus-Leninismus“ vornahm, wurde zweierlei geleistet. Es entstand eine Legitimationsideologie, die die jeweiligen Maßnahmen in der Sowjetunion rechtfertigte und als ,sozialistische apostrophierte. Für Westeuropa entstand mit der Sowjetunion ein abstrakt antikapitalistischer Bezug, der für die kommunistische Arbeiterbewegung in Vergangenheit und Gegenwart realpolitisch bedeutete, daß die unmittelbaren Interessen der Arbeiter gegen die bürgerlichen und sozialdemokratischen Ordnungsvorstellungen organisiert werden können. Diese Realpolitik bleibt trotz aller antikapitalistischer Beteuerungen auf Kriterien bürgerliche Politik beschränkt. Sie definiert Klasseninteresse als ein Interesse, das mit Mitteln von Aktionsformen und Organisationen erreicht werden soll, die selbst Produkte der bürgerlichen Demokratie sind und das sich Sozialismus ausmalt als mehr soziale Gerechtigkeit, die erreicht werden soll durch die Allmacht des Staates, der langsam das Privateigentum zurückdrängt und alle gesellschaftlichen Prozesse unter seine Domäne stellt. Die scheinbar existierende Allgewalt des kapitalistischen Staates wird verzaubert zu den Potenzen des Sozialismus, ohne daß für die Initiative der Arbeiter Platz bleibt, staatliche Funktionen in die eigenen Kontrollorgane zu- 
rückzunehmen. Die bestehende Gesellschaft feiert ihre utopische Auferstehung als sozialistische Idylle. So entlarvt sich der heutige ,Marxismus-Leninismus", reicht er zum Selbstverständnis kommunistischer Arbeiterparteien, als Variante des sozialdemokratischen Utopismus eines Lassalle, Kautsky oder Hilferding. Über eine Absolutsetzung spätkapitalistischer oder staatskapitalistischer Produktionsformen kommt er nicht hinaus und ist somit gegen alle sozialemanzipatorischen Aktionsformen der Arbeiter bei Streiks, Betriebsbesetzungen oder Demonstrationen eingestellt. Politik, die nicht verwaltet werden kann und die nicht den Führungsprinzipien der Partei genügt, ist anrüchig.

Für unsere Fragestellung, die wir in diesem Aufsatz untersuchen wollen, indem wir auf die Traditionen des Lenin'schen Taktik- und Organisationsverständnis eingehen, tauchen zwei Probleme auf. Warum konnte diese Ideologie die einzige Alternative für die russische Revolution formulieren und warum konnte sie sowohl in der westeuropäischen Arbeiter- und Intellektuellenbewegung Fuß fassen?

Für die aktuelle Problemstellung, die unsere Untersuchung politisch motiviert hat, sollen nur kurze Anmerkungen aufgeführt werden. Die Erfahrungen in Italien, Spanien, Portugal aber auch für Frankreich zeigen, daß der „Marxismus-Leninismus" von Parteien, in denen eine relativ starke Arbeitermitgliedschaft vorhanden ist, in dem Maße Veränderungen unterworfen ist, wie die Arbeiterklasse durch die ökonomischen und politischen Bedingungen zu spontanen Widerstandsaktionen gezwungen wird. Der realpolitisch gesetzte Gegensatz zur Monopolbourgoisie und ihres Staates entspricht den Erfahrungen und Absichten der Arbeiter, sich Lohnsenkungen nicht bieten zu lassen und eine Entdemokratisierung der Gesellschaft zu verhindern. In dieser Hinsicht ist diese Ideologie progressiv und an neue Klassenkampfsituationen anpassungsfähig. Das vorgestellte Primat der Politik dieser kommunistischen Parteien, Avantgarde oder bedeutender Bestandteil der Arbeiterbewegung zu werden bzw. zu bleiben, veranlaßt sie zu Modifikationen in Theorie und Taktik. Die Leitsätze des „Marxismus-Leninismus" werden dabei jedoch nicht beeinträchtigt.

Während überall in Westeuropa die Sozialdemokratie weitgehend ihre ideologische und taktische Integration ins bürgerliche Herrschaftssystem vollzogen hat, zwar durch die Sozialpolitik in der Hochkonjunktur Teile der Arbeiterklasse an sich binden konnten, programmatisch aber auf die Stabilisierung kapitalistischer Verhältnisse festgelegt ist, geben die kommunistischen Parteien, da sie von den bürgerlichen und sozialdemokratischen Parteien außerhalb der direkten Regierungsverantwortung gestellt werden, den Anschein als stehen sie praktisch politisch außerhalb dieser Ordnung. Sie bieten sich dadurch an, zum Sammelbecken für proletarische, kleinbürgerliche, bäuerliche und mittelständische Interessen zu werden. Ideologie, zentralistische Partei, Bürokratie und das System der Zwischen- und Nebenorganisationen hält diese Interessen solange zusammen, bis diese Partei praktisch beweisen muß, ob sie innerhalb oder außerhalb buirgerlicher Politik steht.

In Italien, Frankreich und Portugal ist die Wende gekommen und hier wird sich zeigen, ob diese Parteien eine sozialistische Umwälzung einleiten können oder sich gegen die soziale Befreiung der Arbeiter stemmen. 
In den ,marxistisch-leninistischen" Gruppen wie etwa in Westdeutschland, in denen die Intelligenz eindeutig dominiert, verliert der Führungsanspruch der Partei gegenüber den Arbeiterinteressen sich in die Elitevorstellungen der Intelligenz. Das Volk oder entsprechend das abstrakte Proletariat wird Objekt von Projektionen, die nichts anderes darstellen als die vergrößerten Bedürfnisse dieser Intellektuellen. Gegen die Dequalifizierung, Arbeitslosigkeit, Angst werden die bedeutende, politische Rolle, politische Tatkraft und sozialer Mut und Haß gestellt. Im Namen des Volkes oder des Proletariats soll die Welt verändert, d. h. die alte gesellschaftliche Stellung der Intelligenz soll konserviert werden. Sie schanzt sich mit Hilfe dieser Ideologie eine historische Mission zu, Erneurer und Elite der Nation zu sein, die alles zum Besten kehren wird. Diese „Zwischensekten" zwischen Bourgeoisie und Arbeiterklasse immunisieren sich und ihre Parteigänger vom proletarischen Sozialismus und behindern dadurch die sozialistische Parteilichkeit der Intelligenz allgemein. In ihrem Denken sind sie reaktionär und ihre Organisationen sind deshalb nicht Mittel für eine kontinuierliche Politik und Aufklärung, sondern Abklatsch des bürgerlichen Zentralismus und der Gehorsamspflicht in bürgerlichen Parteien. Ihre Zukunftsvorstellungen sind $\mathrm{zu}$ einem "Kasernenhauskommunismus" verkommen, in dem ein despotischer Staat, als Diktatur des Proletariats gefeiert, die Gesellschaft bestimmen soll und in dem sie nichts weiteres sein wollen als die ,neuen ${ }^{66}$ Herren. So reproduziert sich in ihrem Kampf gegen das Bestehende das Alte, die bestehende Gesellschaft.

Diese ideologische Instrumentalisierung des ,Marxismus-Leninismus“, der einmal als die Rechtfertigung der staatlichen Politik der Übergangsgesellschaft genutzt wird, das andere Mal als Variante sozialdemokratischer Taktik der westlich kommunistischen Parteien oder als Spielart des bürgerlichen Elitedenkens herhalten muß, deckt die sozialen und historischen Ursprünge dieser Ideologie auf. Das ist die Grund these unserer Untersuchung, die wir in den folgenden Seiten beweisen wollen. Die Konfrontation der Lenin'schen Politik- und Parteiauffassung mit dem Marx' schen Theorie-Taktik- und Organisationsverständnis würde an dieser Stelle den Aufsatz sprengen. Er ist in einem anderen $\mathbb{Z}$ usammenhang von linker Seite ausführlich analysiert worden (1).

Noch eine Anmerkung ist zu machen. Diese Analyse hat die Untersuchung der ökonomischen und politischen Verhältnisse Rußlands zwischen 1861 und 1918, die in dieser Zeitschrift in der Nr. 11/12 unter dem Titel „Halbheiten in der Úberwindung des Leninismus ${ }^{66}$ vorgestellt wurde, zur Voraussetzung. Nur in diesem Zusammenhang sind die folgenden Ausführungen zu verstehen. Eine systematische Kritik der Ideologie der deutschen Sozialdemokratie fehlt an dieser Stelle. Auf diese Ideologie wird im Rahmen der Darstellung der russischen Sozialdemokratie in dem Maße eingegangen, wie sie das Denken Plechanovs und Lenins beeinflußte. Zum Schluß

1 D. B. Rjasanow, Marx und Lenin nicht nur für Anfänger, Berlin 1973, S. 52 ff und S. $124 \mathrm{ff}$; ders., Zur Geschichte der I. Internationale, in: Archiv des Marx-Engels-Instituts, Moskau 1924; B. Rabehl, Geschichte und Klassenkampf, Berlin 1973, S. 69 und S. 88; U. Wolter, Grundlagen des Stalinismus, Berlin 1975 
dieses Aufsatzes soll die Aufzeichnung der Leninkritik des ,,jungen “ Trotzki auf die andere Fraktion der revolutionär marxistischen Theoretiker verweisen, deren MarXrezeption und Auffassung der Klassenkampfbewegung der Arbeiter sich deutlich von der Ideologie der II. Internationale Unterschied. Zu dieser theoretischen Fraktion gehörten neben R. Luxemburg die westeuropäischen und russischen Linkskom. munisten der zwanziger Jahre. Die Darstellung und Untersuchung dieser Theorie muß ein anderes Mal erfolgen. Hervorzuheben ist noch, daß unsere Untersuchung kein anderes Modell von Politik abgeben soll. Sie fuhrt also kein ,Gegenmodell" zum Leninismus vor und ist deshalb unmittelbar politisch nicht verwertbar. Allerdings hoffen wir, ein Marxverständnis und eine Methode der konkreten Anwendung dieser Theorie in der konkreten Analyse darzulegen, die politisch fruchtbar werden können.

\section{Die Entstehung der russischen Sozialdemokratie}

Bei der Interpretation des Entwicklungsprozesses der verschiedenen Fraktionen der russischen revolutionären Bewegung, in unserem Zusammenhang namentlich die der Bolschewiki, kommt der Analyse ihrer Entstehung große Bedeutung zu. Denn die Besonderheiten der russischen Gesellschaftsformation wurden in diesem Prozeß ideell reflektiert und führten zur Verankerung bestimmter Theorie- und Taktikvorstellungen in dieser Bewegung. Es ist im Verlauf der Einschätzung der Fortentwicklung der russischen Sozialdemokratie und des russischen Marxismus zu untersuchen, inwiefern bestimmte Traditionen der revolutionären Intelligenz als konstitutives Merkmal beibehalten oder unter dem Druck der gesellschaftlichen Entwicklung und der Radikalisierung der Klassenkämpfe überwunden werden können, oder ob umgekehrt, in spezifischen gesellschaftlichen Situationen der Veränderung des Kräfteverhältnisses zwischen den Klassen gerade wieder bestimmte, teilweise sogar bereits zurïckgenommene frühere Theorie- und Taktikvorstellungen reaktualisiert werden, aber im Kontext der veränderten gesellschaftlichen Beziehungen neue Qualität erlangen.

Die relative ökonomische und soziale Rückständigkeit Rußlands bei gleichzeitiger Einbeziehung in den kapitalistischen Weltmarkt und das daraus resultierende bunte Nebeneinander der verschiedensten Stufen der Zivilisation und die durch die despotische Autokratie erwirkte geistige Isolation und Stagnation mußte zu einem eben solchen Nebeneinander der ,seltsamsten und unmöglichsten Ideenkombinationen“ (1a) führen. Der ungleiche und kombinierte Charakter der gesellschaftlichen Entwicklung schlägt sich auch in der Artikulation der revolutionären Programme der fortschrittlichen Intelligenz nieder und schreibt der russischen revolutionären Bewegung einen anderen, weniger organischen Entwicklungsgang als in den entwickelten Industrienationen vor, indem sich in eigentümlicher Weise die Traditionen der russischen Intelligenz mit der Übernahme ,,westlicher" ${ }^{6}$ Theorien paaren, ob- 
wohl zwischen diesen Polen teilweise heftige Auseinandersetzungen geführt werden.

Die Intelligentsia in Rußland, in dem sich seit der Bauernreform 1861 der Feudalismus schneller zersetzte, als sich die bürgerliche Gesellschaft herausbildete, war sowohl Produkt der Auflösung der alten Stände, wie der Erfordernisse neuer militärischer und industrieller Errungenschaften. War sie zum einen für Staat und Industrie notwendig, so fand sie andererseits vielfach kein angemessenes Arbeitsfeld. Ihre schlechten Ausbildungs-, Arbeits- und Lebensbedingungen und die ideologische Willkür und Borniertheit der zaristischen Despotie, machten diese Schicht als fast einzige für revolutionäre Ideen anfällig (2). Die Intelligenz wurde so zum Vorboten großer gesellschaftlicher Erschütterungen, aber sie war von der Masse der Bevölkerung isoliert und begann bald anstelle dieser Massen zu handeln.

Bereits 1825 versuchten die Dekabristen, junge Adlige und Offizierssöhne, in einem vergeblichen Aufstand eine Liberalisierung der Gesellschaft zu erzwingen. Die europäischen Revolutionen von 1848 und die Rolle, die sowohl der Zarismus, als aber auch die Bourgeoisie der einzelnen Länder in ihr spielten, sowie die Krise der russischen Gesellschaft und die „Entdeckung" der Obscina für die Wissenschaft 1847 durch den westfälischen Baron von Haxthausen (3) gaben der Intelligentsia neue Impulse. Die wesentliche Frage, an der sie sich auch spaltete, war die, ob Rußland des westeuropäischen Weg nachvollziehen müsse, oder ob es eine eigene historische Chance besitze, zu einer höheren kulturellen und sittlichen Gesellschaftsordnung zu kommen, wie es die „Slowophilen“" behaupteten. In Anknüpfung an die panslawistischen Traditionen eines großrussischen Reiches, wurde der durch die Obscina jetzt erwiesene Kollektivgeist der Russen der Verrohung Westeuropas gegenüber gestellt. A. S. Chomjakow, die Brüder Konstantin und Iwan Aksakow und J.F. Samarin waren die wesentlichen Vertreter dieses Messianismus der Rückständigkeit (4). Waren die klassischen Slawophilen eine relativ homogene Gruppe, die dem offiziellen zaristischen Volkstümlertum (S. S. Uwarow), oder dem, wie es auch genannt wurde, offiziellen Nationalismus und den „Westlern“" gegenüberstanden, so kann dies von den letzteren nicht behauptet werden, sie fraktionierten sich in mehrere Richtungen, die ungefähr denen Westeuropas entsprachen. Konservative, Liberale, Radikale und Sozialisten fanden sich in ihren Reihen. Während einige Fraktionen die politischen und ökonomischen Interessen der verschiedenen

2 Vgl. dazu Leonhard Schapiro, Die vorrevolutionäre Intelligentsia und die gesetzliche Ordnung, und Boris Elken, Die russische Intelligentsia am Vorabend der Revolution, in: Richard Pipes (Hrsg.), Die russische Intelligentsia, Stuttgart 1962, S. 33-64

3 Die Veröffentlichung erschienen von 1847 bis 1852 unter dem Titel: Studien über die inneren Zustände, das Volksleben und insbesondere die ländlichen Einrichtungen Rußlands

4 Vgl dazu S. V. Utechin, Geschichte der politischen Ideen in Rußland, Stut tgart 1966, S. $78-89$ 
Schichten der Bourgeoisie ausdrückten, bekannten sich die anderen mehr zur Sache des Volkes und forderten dessen Befreiung. W. G. Belinskij und vor allem Alexander I. Herzen waren aber bereits die Vorläufer des Populismus und Schöpfer eines russischen Sozialismus, der den westlichen Gedanken des Sozialismus mit der slawophilen Bewunderung für die russischen Bauern und deren Obscina verschmolz und damit die ideologische Grundlage für die Narodniki abgab. N. G. Tschernyschewskij, P. N. Tkatschow, N. P. Ogarjow (5) waren die wesentlichen Vertreter dieser fribhen Sozialisten, die die unmittelbaren Vorläufer der Narodniki, deren geistige Väter vor allem P. L. Lawrow und auch M. Bakunin waren (6). Sie entwickelten mit unterschiedlichen Modifikationen ähnliche Systeme eines abstrakten Sozialismus, Anarchismus oder Nihilismus, die letztlich in einen Mythos des Volkes ausarteten und somit philosophisch teilweise an die offizielle zaristische Tradition anknüpfte und auch Elemente der klassischen konservativen Slowophilen in sich aufnahm, die dem russischen Volk besondere Qualitäten und deswegen eine historische Mission zuschreiben wollten.

Zunächst waren es seit den 60er Jahren die aufklärerischen Ideen der Westler, als Gegenfraktion zu den Slawophilen, mit denen die Intelligenz die Masse befruchten und die Gesellschaft liberalisieren wollte. Im Namen des Volkes sprechend idealisierte diese Intelligenz die Mehrheit des Volkes, die Bauern und die Obscina mit dem Mythos eines agrarischen Volkssozialismus, wobei ihr in ihrem Selbstverständnis gleichzeitig die entscheidende gesellschaftliche Funktion als subjektiven Träger des Fortschritts zufiel. Trotzki charakterisiert dieses Spezifikum einer revolutionären aber isolierten Intelligenz folgendermaßen: „Die Geschichte der russischen Intelligenz spielt sich zwischen diesen beiden Polen ab: Der Selbsterniedri* gung und dem Hochmut, als dem kurzen und dem langen Schatten ihrer sozialen Schwäche" (7). Den notwendig scheiternden Versuchen einer derartigen Volksaufklärung und des anschließenden „Ins-Volk-Gehen“ (8), folgte konsequent bald darauf in den 70er Jahren eine Phase des individuellen Terrors, in der mit neuen Mitteln die alten Ziele erreicht werden sollten. Die Intelligentsia sprach jetzt nicht mehr nur für das Volk, sie handelte auch an dessen Stelle. Ihr heroischer Kampf mit der Ochrana, der allmächtigen zaristischen Geheimpolizei, sollte das Fanal für den Volksaufstand werden. Die 1862 erfolgte Gründung der Organisation „Semlja i Wolja" (Land und Freiheit) war der erste Ausdruck dieser revolutionären Strömung des Volkstümlertums. Der die Wirtschaft weiter zerrüttende Krieg mit der Türkei und die diplomatische Kapitulation des Zarismus auf dem Berliner Kongreß 1879 und die wieder zunehmende Verschärfung der despotischen Maßnahmen und die

$5 \quad$ Zur Stellung von Marx und Engels zur revolutionären Bewegung in Rußland vgl. Kurt Mandelbaum, Marx, Engels, Lenin, Zur Vorgeschichte der russischen Revolution, in: ders., Sozialdemokratie und Leninismus, Berlin 1974, S. 48-78

6 Zur Darstellung der revolutionären Traditionen der Vorläufer der Sozialdemokratie vgl. Adam B. Ulam, Lenin and the Bolshewiks, London/Glasgow 1965, Kapitel 2, S. 27-124

7 Leo Trotzki, Der junge Lenin, Frankfurt 1971, S. 31

8 Diese Parole wurde von dem Anarchisten Bakunin geprägt 
Massenprozesse 1874 gaben erneut Anlaß zu einer Diskussion über die einzuschlagende Taktik in den Reihen der Narodniki und führten schließlich am 15.8.1879 zum Bruch und dem Entstehen zweier Fraktionen. Zum einen die der ,Narodna Wolja“" (Volkswille oder Volksfreiheit) und zum anderen die der „Tschorny Peredjel $^{66}$ (Schwarze Umteilung), die die direkte Vorläuferorganisation der ersten russischen sozialdemokratischen Gruppierung war. Differenzen bestanden im wesentlichen in drei Fragen, obwohl festzuhalten ist, daß im Laufe der Entwicklung wieder eine Annäherung stattfand.

Die erste Frage betraf das politische Ziel des Kampfes. Die Narodnowolzen erklärten als ihr offenes Ziel, die Erkämpfung politischer Freiheiten und die Errichtung einer Konstituante als Ausdruck des Prinzips der Herrschaft des Volkswillens (9), während die Tschorniperedjelzy betonten, daß eine alleinige Erkämpfung der politischen Freiheiten nicht genügen könne, um einen ,idealen“ Staat aufzubauen, es komme vielmehr darauf an, das Volk durch die in der revolutionären Partei vertretene Intelligenz zu organisieren, da sich die offiziellen Staatsorgane nicht zur Verkörperung des Volkswillen eignen, sondern vielmehr der Bourgeoisie das politische Terrain eröffnen würden. Dabei sollen nicht nur die Bauern, sondern auch die städtischen Arbeiter mit einbezogen werden. Ihre Parole lautete daher: „Bauer, nimm das Land; Arbeiter, die Fabrik“ (10). Es wurde das „Primat der Politik" der Narodnowolzen abgelehnt und sich mehr auf die alten Traditionen der Volkstümler berufen. Den zweiten Diskussionspunkt markiert die Frage der Anwendung des Terrors. In beiden Fraktionen war unbestritten, daß er eine notwendige Aktionsform gegen den Despotismus ist. Die Narodnawolja erklärte den Terror zur wichtigsten Kampfform. Als das Hauptangriffsziel wurde die Regierung und namentlich der Zar angegeben. Der Terrorismus sollte eine Verunsicherung der Herrschenden und die Bildung einer konstituierenden Versammlung bewirken. Bei der anderen Fraktion dagegen wurde versucht, den Terror in allgemeine propagandistische Aktionen mit einzubeziehen, sollte durch den Terror der Glaube des Volkes an seine eigene Kraft gestärkt werden, wie es in der Nr. 4 ihrer Zeitung heißt (11). Aber da das Hauptziel dieser Organisation die Bildung einer Volkskampfpartei war, dürfe sich der Kampf nicht allein gegen die Regierung konzentrieren, es wurde daher vor allem Wert auf systematischen agrarischen und Fabrikterror gelegt.

Der dritte Streitpunkt betraf die Organisationsfrage. Die unterschiedlichen Schwerpunkte in der Tätigkeit der beiden Fraktionen mußten auch ihren Niederschlag in unterschiedlichen Organisationsformen finden. Der Kampf gegen den Zaren und seine Regierung erforderte von den Mitgliedern des „Volkswillens" einen extrem hohen Grad an Konspiration, der nur durch die stärkste Zentralisierung gewährleistet werden konnte. Schon in der ,Semlja i Wolja ${ }^{6}$, die eine Abkehr von

9 Dazu Alphons Thun, Die Geschichte der revolutionären Bewegung in Rußland, Leipzig 1883 , S. $185 \mathrm{ff}$

10 Ebd., S. $225 \mathrm{ff}$

11 Ebd., S. 232 
den föderativen Prinzipien der vorangehenden Periode zugunsten der Straffung der Organisation bedeutete, wurden Vorschläge diskutiert, die eine Unterordnung der Ortsgruppen unter das Zentrum, der Minderheit unter die Mehrheit u. ä. zum Inhalt hatten (12). Dieses Prinzip wurde von den Narodnowolzen im Extrem verwirklicht. Sie bestanden im Grunde nur aus dem Exekutivkommitee, das die 28 Mitglieder der „ersten Stunde ${ }^{66}$ umfaßte, die praktisch unkontrollierbar waren. Ihm untergeordnet waren die Lokal und Spezialvereine, die nach drei Vertrauensgraden gestaffelt waren und je nach dem Grad zur Realisierung der Anweisungen des Kommitees arbeitsteilig und in festem Auftrag herangezogen werden konnten (13). Insgesamt hat die Mitgliederzahl aller Gruppen niemals mehr als 500 betragen, einige Tausend standen ihr wohlwollend gegenüber, ohne ihr beizutreten (14). Die Tschornyperedjelzy, deren Zeitung sich das „Organ der sozialistischen Föderalisten “ nannte, betonten dagegen zunächst eine lockerere Organisationsform, die ihrem spezifischen Vorhaben, der Organisation einer Volkskampfpartei auf dem Land und in der Stadt, mehr entgegenkam und lehnte strikte Zentralisierung und absolute Unterordnung als Jakobinertum ab, das die Apathie der Massen nur noch vertiefe, während es das Gegenteil zu erreichen gelte. Aber unter dem Druck der schärfer werdenden politischen Reaktion nähern sie sich in dieser Frage der ,Narodna Wolja ${ }^{66}$ wieder an, die auch dieser Bewegung insgesamt ihren prägenden Ausdruck verleiht und ihren politischen Höhepunkt in der Ermordung Alexander II. am 1.3.1881 findet, während die "Schwarze Umteilung" weitgehend wirkungslos operiert. Sie erlangt Bedeutung als die direkte Vorläuferin der ersten russischen sozialdemokratischen Organisation „Gruppe der Befreiung der Arbeit“, die 1883 im Schweizer Exil gegründet wurde. Deren Organisatoren Plechanow, Vera Sassulitsch, Axelrod, Deutsch, Stephanowitsch $u$. a. kamen sämtlichst aus dieser Gruppierung.

Der Terrorismus, zunächst Abwehrform gegen den Zarismus und Racheakt für ermordete Genossen, verwandelte sich mit innerer Logik zum selbständigen System des politischen Kampfes, das im Gegensatz zu den Hoffnungen der Intelligenz, einen Massenkampf a priori ausschloß, da keine revolutionäre Situation in Rußland bestand. Die Kompensation der sozialen Schwäche der Intelligentsia konnte nur notdürftig mit Dynamit gelingen, der Verzicht auf den Massenkampf mußte die sozialistischen Ziele der Intelligentsia in subjektive Illusionen verwandeln(15), denen kein Korrektiv mehr gegenüberstand. Die Idealisierung des Volkes mußte in Pessimismus umschlagen, wenn sich erwies, daß das Volk nicht nach den Idealen der Intelligenz handelte und handeln konnte. So ist es auch nicht verwunderlich, daß das Scheitern des Terrorismus nach der Zerschlagung der „Narodna Wolja“ eine gegenläufige Bewegung auslöste, daß die ehemaligen Terroristen und Anarchisten objektiv zum Vorläufer des Liberalismus wurden und viele von ihnen selbst ihre

12 Ebd., S. 166, vgl auch Utechin, a.a.O., S. 116, der eine ausführliche Darstellung des Organisationskonzeptes der Semlja i Wolja gibt, den Ogarjow ausgearbeitet hatte.

13 Ebd., S. 186, 203-06, 214-19

14 Ebd., S. 219

15 Trotzki, a.a.O., S. $44 \mathrm{f}$ 
Illusionen auf einen Agrarsozialismus aufgaben und zu Parteigängern des Zarismus wurden (16), der als einzige gesellschaftliche Kraft erschien, die noch einen Fortschritt ermöglichen könne und als, aufgeklärter Absolutismus ${ }^{66} \mathrm{das}$, was die Bauern nicht verwirklichen konnten, von oben einführen sollte. Die Apathie des Landes und besonders die umfassende Agrarkrise zu Beginn der 90er Jahre verstärken diese Tendenz noch in dieser intellektuellen Fraktion.

Gleichzeitig gaben aber die Hungerjahre und die unter dem Finanzminister Witte forcierte Industrialisierung und der Versuch der Lösung der Agrarkrise durch eine Kapitalisierung der Landwirtschaft sowie die zunehmenden Streikaktionen der Arbeiter den Diskussionen der revolutionären Intelligenz neue Impulse.

Eine Renaissance des Marxismus setzte in Rußland in dieser Periode ein, während es zuvor seit 1883 wesentlich die Exilrussen der ,Gruppe der Befreiung der Arbeit" waren, die bestimmte marxistische Positionen vertraten. Der erste Band des „Kapitals“ war bereits 1872 in 3.000 Exemplaren in Rußland erschienen. Mit der Übersetzung hatte Bakunin begonnen, sie wurde von German Lopatin fortgesetzt und dem bedeutendsten Nationalökonomen der ,Narodniki" N. F. Danielson (Nikolaion) beendet. Doch wurde das Kapital von den Volkstümlern nicht als wissenschaftliche Analyse der Anatomie der bürgerlichen Gesellschaft interpretiert, sondern an erster Stelle als moralische Verurteilung der Ausbeutung im Kapitalismus, der gegenüber die kollektive Lebensweise der Dorfgemeinschaft und der Genossenschaften idealisiert wurden. Die große Streikbewegung der russischen Arbeiter, die ihren ersten Höhepunkt 1884/86 fand und einige Erfolge erzielte (17), bei der gleichzeitig immer offener in Erscheinung tretenden Stagnation der Landwirtschaft, die beginnende Industrialisierung waren Faktoren, die andere soziale Kräfte als die Bauern, die über lokale Aufstandsversuche nicht hinauskamen, ins revolutionäre Kalkül brachten. Die Überwindung der Depression der europäischen Arbeiterbewegung, die Pariser Kommune, die englischen Dockerstreiks und das Auftreten eines kämpferischen Trade-Unionismus, die Wahlerfolge der deutschen Sozialdemokratie trotz des Sozialistengesetzes und die im Jahre 1889 in Paris erfolgte Gründung der II. Internationale, sowie die politische Sackgasse, in die die russische Intelligentsia seit der Zerschlagung der „Narodna Wolja“ geraten war, waren wesentliche Faktoren, die eine neue Interpretation des Marxismus in Rußland in Gang brachten. Die entscheidende Rolle bei dieser teilweisen Umorientierung der russischen Intelligenz spielte der ehemalige Narodnik Georgij W. Plechanow. Er wurde damit zugleich für die spätere Generation der russischen Marxisten prägend, die weitgehend auf seinen Analysen und Einschätzungen aufbauten. Er stellte gewissermaßen das Vermittlungsglied zwischen der russische Intelligenz und ihrer Traditionen, zu denen der Sozialdemokratie Deutschlands und der II. Internationale dar. Die Verquickung dieser beiden Elemente war konstitutives Merkmal des russischen Marxismus.

Auf diesen Zusammenhang weist Engels in dem bereits zitierten Brief an Plechanow (Fn. 1) hin.

17 Vgl. Julius Martow, Geschichte der russischen Sozialde mokratie, Berlin 1926, S. 12 f 
Die erste sozialdemokratische Organisation wurde 1883 von den in der Schweiz nach Genf emigrierten Exilrussen der ,Tschorny Peredjel“ nach deren Scheitern gegründet (18). Die „Gruppe der Befreiung der Arbeit ${ }^{66}$ erlangte weniger Bedeutung als unmittelbar politisch wirkende Kraft, sondern vielmehr als richtungsweisender Kritiker der volkstümlerischen Idealisierung der Obscina, dem gegenüber in der von Plechanow verfaßten Programmschrift der Gruppe „Unsere Meinungsverschiedenheiten“" erklärt wird, daß dem Kapitalismus, ,nicht allein die nächste $\mathrm{Zu}$ kunft, sondern auch die Gegenwart Rußlands" (19) gehöre. Die von den Narodniki mystifizierten rückständigen Formen der Landwirtschaft werden mit naturgesetzlicher Gewalt zerschlagen. Da sie das Produkt der Rückständigkeit und nicht des Kapitalismus seien, gelte es, den Kapitalismus als der nächsten Etappe der gesellschaftlichen Entwicklung zur Reife kommen zu lassen. Diese Auffassung wurde als „Einsicht in die historische Notwendigkeit ${ }^{6}$ interpretiert, die mit dem gesellschaftlichen Fortschritt identisch sei (20). Das Vernüftige, also der Kapitalismus, muß sich gegen die Unvernunft, den Anarchronismus der Autokratie durchsetzen. Die Intelligenz müsse sich auf den Boden des Marxismus stellen, der in dieser Weise interpretiert wurde, und Propaganda zu dessen Verbreitung unter den Arbeitern betreiben.

Marx hatte schon 1877 an die Redaktion des „Otetschestwennyje Sapiski“ anläßlich eines Artikels des Ideologen der Volkstümler Michailowski geschrieben: „Strebt Rußland dahin, eine kapitalistische Nation nach westlichem Vorbild zu werden - und in den letzten Jahren hat es sich in dieser Richtung sehr viel Mühe kosten lassen -, so wird es dies nicht fertig bringen, ohne vorher einen guten Teil seiner Bauern in Proletarier verwandelt zu haben; und dann, einmal hineingerissen in den Wirbel der kapitalistischen Wirtschaft, wird es die unerbittlichen Gesetze dieses Systems zu ertragen haben, genauso wie die andern profanen Völker. Das ist alles. Aber das ist meinem Kritiker zu wenig. Er muß durchaus meine historische Skizze von der Entstehung des Kapitalismus in Westeuropa in eine geschichtsphilosophische Theorie des allgemeinen Entwicklungsganges verwandeln, der allen Völkern schicksalsmäßig vorgeschrieben ist, was immer die geschichtlichen Umstände sein mögen, in denen sie sich befinden, um schließlich zu jener ökonomischen Formation zu gelangen, die mit dem größten Aufschwung der Produktivkräfte der gesellschaflichen Arbeit die allseitigste Entwicklung des Menschen sichert $^{66}(21)$. Engels hat diesen, damals von Marx nicht abgeschickten Brief, nach

18 Dazu besonders die Arbeiten von Samuel H. Baron: Plekhanov, the Father of Russian Marxism, Stanford/California 1963, Plekhanov on Russian Capitalism and the Peasant Commune, 1883-85 in: American Slavic and East European Revicw, Jg. XII, 1953, S. 463-74, Plekhanov and the Origins of Russian Marxism, in: Russian Review, Jg. XIII, 1954, S. 38-54 und The First Decade of Russian Marxism, in: ASEER, Jg. XIV, 1955, S. $315-30$

19 G. W. Plechanow, Unsere Meinungsverschiedenheiten (russ.), Genf 1884, zitiert nach: Dietrich Geyer, Lenin in der russischen Sozialdemokratie, Köln 1962, S. 11

20 Ebd.

21 in: MEW 19, S. 111 
dem Erscheinen von ,Unsere Meinungsverschiedenheiten ${ }^{66}$ am 6.3 .1889 offensichtlich in bestimmter Absicht an das Mitglied der "Gruppe der Befreiung der Arbeit" Vera Sassulitsch geschickt (22). Der ,ennuyante Doktrinarismus" (23) der Tschorny Peredjel, die von ihrem sicheren Exil aus im Namen der Propaganda die politischen Aktionen der Terroristen gegen den Hort der europäischen Reaktion verdammten, war Marx schon 1880 aufgefallen. Die Annäherung an den Marxismus durch Plechanow bedeutete zugleich aber dessen spezifische Revision, die sich vor allem in dem grundlegenden methodischen Irrtum äußerte, den Marxismus nicht als ideelen Reflex der wirklichen Verhältnisse zu interpretieren (24), sondern ihn als ein geniales Verstandesprodukt darzustellen, als „ein Ideal, das der ökonomischen Wirklichkeit entspricht (...) Wenn über ,Ideale ${ }^{6}$ gesprochen wird, so muß man sagen, daß die Marx'sche Theorie die idealistischste Theorie ist, die je in der Geschichte des menschlichen Denkens existiert hat ${ }^{6}$ (25) und als ideengeschichtliche Evolution zu erklären sei, als geniale Korrektur falscher, weil der Wirklichkeit nicht entsprechender Ideale. „Die Marx ${ }^{6}$ sche Geschichtsauffassung, die die Ignoranten für eng und einseitig halten, ist tatsächlich das legitime Produkt einer langen Entwicklung der historischen Ideen“" (26) schreibt er 1896 in seinen „Beiträgen zur Geschichte des Materialismus ${ }^{6 \text {, }}$ in denen er eine Auseinandersetzung mit den französischen Materialisten Holbach, Helvetius u. a. führt, um in der Kritik an deren Glauben an eine aufgeklärte Absolutie auch Kriterien für eine Kritik der russischen Intelligenzfraktion zu gewinnen, die sich ebenfalls dem Zarismus wieder zuzuneigen begann. Demgegenüber betont Plechanow die Bedeutung des Materialismus, um die Notwendigkeit der Durchsetzung der kapitalistisschen Verhältnisse in Rußland als einzig möglicher Form des gesellschaftlichen Fortschrittes zu unterstreichen. „Nun fällt aber, sobald wir uns auf den monistischen Standpunkt stellen, der Erfahrung die Entscheidung darüber zu, welche der beiden Theorien, der Idealismus oder der Materialismus, besser die Phänomene erklärt, mit denen wir es beim Studium der Natur und der menschlichen Gesellschaft zu tun haben" (27). In seiner Interpretation bedeutet daher die dialektische Methode als der ,charakteristische Zug des modernen Materialismus" (28), ... daß wir ihr die Auffassung der menschlichen Geschichte als eines gesetzmäßigen Prozesses verdanken“(29). Die konkreten Unterschiede der einzelnen Gesellschaftsformationen, die, zwischen ursprünglicher und kapitalistischer Akkumulation und die widersprüchlichen Ergebnisse der Einbe-

$22 \mathrm{Vgl}$ auch den Brief Engels an Vera Sassulitsch vom 23.4.1885, MEW 36, S. $304 \mathrm{ff}$

23 Karl Marx am 5.11.1880 an Friedrich Sorge, MEW 34, S. 477

24 Dazu D. Rjasanow, Marx und Engels (nicht nur) für Anfänger, Berlin 1973

25 G. W. Plechanow (unter dem Pseudonym N. Beltow), Zur Frage der monistischen Geschichtsauffassung, Berlin 1956, S. 227-8

26 Ders., Beiträge zur Geschichte des Materialismus, Berlin 1957, S. 161 (Diese und die folgenden Hervorhebungen im Original)

27 Ebd., S. 151/2, siehe auch: Zur Frage der monistischen Geschichtsauffassung, a.a.O., S. 304

28 Ebd., S. 149

29 Ebd., S. 139 
ziehung Rußlands in den kapitalistischen Weltmarkt, können in dieser Interpretation nur noch formalen Eingang finden (30). Die Unterschiede im ,natürlichen Milieu" werden durch die ,unabhängige Logik" der sozialen Bewegung eliminiert, in Rußland entwickelt sich ,mit Notwendigkeit... kapitalistisches Eigentum" (31). Diese Formalisierung des Marxismus, der „einen sicheren Weg wissenschaftlicher Untersuchung" ${ }^{6}(32)$ weist, in ein abstraktes Deduktionsmodell deutet den Rückfall in ein bürgerliches Theorie- und Methodenverständnis an. So ist die Marx'sche Erkenntnistheorie in seiner Interpretation ,eigentlich die Erkenntnistheorie Feuerbachs (...), nur vertieft durch die geniale Korrektur, die Marx an ihr vornahm" (33). Diese Reduktion der materialistischen Dialektik auf einen naturwissenschaftlichen Materialismus, eine allgemeine Evolutionsphilosophie, in der sich der gesellschaftliche Fortschritt gesetzmäßig kraft seiner inneren Logik verwirkliche, ist die Basis für eine Theorie der mechanischen Abfolge bestimmter historisch notwendiger Gesellschaftsetappen, der gegenüber das handelnde Eingreifen des historischen Subjektes als nackter Anarchismus erscheinen muß (34), wenn es über das Modell der postulierten „historischen Notwendigkeiten“ hinwegschreitet. „Was vernünftig ist, das wird auch wirklich, und die ganze unwiderstehliche Kraft der ökonomischen Notwendigkeit nimmt ihre Verwirklichung auf sich“" (35).

Dieses letztendlich bürgerliche Theorieverständnis, das offen an die revolutionären bürgerlichen Materialisten der Vor-Marx-Periode, aber auch teilweise, wie das letzte Zitat zeigt, an die Metaphysik Hegels anknüpft (36), und deutlich die Befangenheit Pledanows in der Marxismusrezeption der deutschen und österreichischen Sozialdemokratie beweist, mußte aber dennoch unter den besonderen Verhältnissen Rußlands noch eine andere Ausprägung finden, da es für Plechanow offensichtlich war, daß die russische Bourgeoisie ein Bündnis mit der Autokratie eingegangen war und keine klassisch-demokratische Rolle zu spielen mehr in der Lage war. Die Kombination der Verstärkung der politischen Despotie des Zarismus unter Alexander III., die sich nicht nur gegen die Bauern, Arbeiter und Studenten richtete, sondern auch durch die Beschneidung der Funktionen der Semstwoverwaltungen gegen die rudimentären Organisationsformen der liberalen Bourgeoisie, ohne daß diese dagegen radikal opponierte, mit einer forcierten Industrialisierung, $d . h$. der ökonomischen Stärkung, der Bourgeoisie zeigten den Opportunismus und die völlige politische Impotenz dieser Klasse an. Hatte er noch 1892 eine Allianz aller Kräfte gegen den Zarismus im Auge (37), so zieht Plechanow bereits 1896 den

Ebd., S. 209/10

31 Ebd., S. $170 / 1$

32 Ebd., S. 189

33 Ders., Grundprobleme des Marxismus, Wien/Berlin 1929, S. 24/5

Vgl. ders., Anarchismus und Sozialismus, Berlin 1894

Ders., Beiträge zur Geschichte des Materialismus, a.a.O., S. 212

36 Zu Plechanows Hegelinterpretation vgl, ders., Zu Hegels sechzigstem Todestag, in: Neue Zeit, Jg. X (1891/2), Bd. 1, S. 198-203, 236-243 und 273-282

Vgl dazu D. Geyer, a.a.O., S. $20 \mathrm{ff}$ 
folgenden Schluß: „Die Bourgeoisie ist heutzutage eine reaktionäre Klasse geworden; sie bemüht sich, ,das Rad der Geschichte zurückzudrehen. Ihre Ideologen sind nicht einmal imstande, den ungeheuren wissenschaftlichen Wert der Entdeckungen von Marx zu begreifen" (38).

Der immanente Widerspruch zwischen der Notwendigkeit der Durchsetzung kapitalistischer und demokratischer Verhältnisse gegen den Widerstand der Autokratie bei gleichzeitigem Fehlen einer dazu fähigen Bourgeoisie bleibt bei Plechanow ungelöst und wird nicht einmal problematisiert, weil er in keiner Weise den Unterschied zwischen kapitalistischen und sozialistischen Formen der Vergesellschaftung der Arbeit thematisiert, diese Form-Inhalt-Dialektik bei ihm auf eine kausale Mechanik reduziert wird. Kurzerhand werden die sozialdemokratischen Arbeiter zu Anhängern des „Fatalismus" und der „Notwendigkeitslehre“ erklärt (39), sie sollen also die Aufgaben der Bourgeoisie lösen und ihre eigenen Emanzipationsinteressen denen der geschichtlichen Notwendigkeit unterordnen, die die Intelligenz dem Proletariat klarzumachen bereit ist (40). Die Revision des Marxismus in eine Industrialisierungskonzeption im Rahmen der bürgerlichen Gesellschaft und damit des historischen Fortschritts ist hier angelegt, denn in Plechanows Augen würde die Kapitalisierung Rußlands auch dessen „Europäisienung“ bedeuten (41). So prophetisch sein Ausspruch 1889 auf dem Gründungskongress der II. Internationale, dem Internationalen Arbeiterkongress in Paris: „Die russische revolutionäre Bewegung wird als Arbeiterbewegung siegen, oder sie wird überhaupt nicht siegen!" (42) auf den ersten Blick zu sein scheint, so wird bei einer genaueren Analyse deutlich, daß sein Engagement für die Arbeiterklasse nur auf das völlige politische Versagen der Bourgeoisie zurïckzuführen ist und letztlich moralisch, d. $h$. ohne wissenschaftliche Begründung bleiben muß und dazu tendiert, den realen Emanzipationsinteressen des Proletariats in den Weg zu treten, sobald es in seinen Kämpfen den Rahmen der bürgerlichen Gesellschaft und damit auch einer derartigen bürgerlichen Ideologie, zu sprengen droht. So wie er die Genesis des wissenschaftlichen Sozialismus nicht aus der gesellschaftlichen Entwicklung des Kapitalismus und als Produkt der radikalen Klassenkämpfe interpretiert, sondern als geniales Resultat autonomen Denkens, so bleibt für die Intelligenz bei ihm auch deren traditionelles Selbstverständnis unangetastet. Sie muß ,die Führung der Arbeiterklasse in der geplanten Befreiungsbewegung“ übernehmen, ,muß ihr ihre politischen und ökonomischen Interessen erklären und muß sie vorbereiten auf eine unabhängige Rolle im sozialen Leben Rußlands" (43).

Plechanow, Beiträge zur Geschichte des Materialismus, a.a.O., S. 219

39 Ebd., S. 220

Ders., Zur Frage der monistischen Geschichtsauffassung, a.a.O., S. 282

41 Vgl. dazu ders, Rußland vor einem Regimewechsel, in: Neue Zeit, Jg. XIII (1894/5), Bd. 1 , S. $228-34$ und $266-73$

42 Ders, in: Protokolle des Internationalen Arbeiter-Congresses zu Paris vom 14.-20. Juli 1889 , Nürnberg 1890, S. 62 ff

43 Ders., zitiert nach B. Rabehl, Marx und Lenin, Berlin 1973, S. 206 
Steht Plechanow hier zwar noch mit beiden Beinen in der volkstümlerischen Tradition, deren Dienst am Volke sich auf dessen Führung beschränkt, so haben sich inzwischen aber die zu führenden Klassen geändert, statt der Bauern nun die Arbeiter. Plechanow befindet sich deshalb mit dieser Position in der nach der Agrarkrise neuerlich aufbrechenden Diskussion in den Reihen der russischen Intelligentsia zwischen den Narodniki einerseits und den legalen Marxisten andererseits.

Im Jahre 1893 erschien das von Danielson verfaßte Buch „Die Volkswirtschaft in Rußland nach der Bauernemanzipation" (44), in dem der bedeutenste ökonom der Neonarodniki deren Anschauung darlegte. Er mußte jetzt zwar anerkennen, daß es einen Kapitalismus in Rußland gäbe und die Landgemeinschaft ihrem Untergang zustrebe (45), betonte aber gleichzeitig, daß der Kapitalismus in Rußland dennoch keine Chance der Durchsetzung habe, da er, vom Weltmarkt ausgeschlossen, keinen inneren Markt habe und kurz vor seinem Untergang stehe, weil er in Rußland auf einen Boden verpflanzt sei, ,der dazu gar nicht geeignet war" (46). Dieser Einschätzung traten nicht nur die Gruppe um Plechanow entgegen, sondern vor allem auch die Fraktion um P. Struve, Tugan-Baranowski, Bulgakow und Skvorcow, die später als, ,legale Marxisten “ bezeichnet wurden (47). Bereits 1893 hatte Struve im Berliner ,Socialpolitischen Centralblatt" einen Artikel veröffentlicht, in dem er erklärte, daß es zur ",historischen Mission" des Kapitalismus gehöre, sich auch in Rußland einen tragfähigen ,,einheimischen Markt ${ }^{6} \mathrm{zu}$ schaffen (48). Im Herbst 1894 erschien dann sein Hauptwerk „Kritische Bemerkungen zur Frage der ökonomischen Entwicklung Rußlands“, in dem er extensiv den wirtschaftlichen und kulturellen Fortschritt Rußlands mit dessen Entwicklung zum Kapitalismus verband und zum Sturze der Autokratie führen müsse, die sich nur durch die kulturelle Unmündigkeit des Volkes halten könne. Gegen den Narodnitschestwo gewandt, betonte er: „Sympathie mit dem arbeitenden Volke ist kein Monopol der Narodniki..., und wir fühlen auch ein tiefes Mitleid mit dem leidenden Märtyrervolke. Das Bild seines Ruins zeigt besser als alles andere seine kulturelle Hilflosigkeit. (...) Laß $3 t$ uns denn unsere kulturelle Rückständigkeit eingestehen und beim Kapitalismus in die Lehre gehen!" (49). Die platte Apologie des Kapitalismus im Namen des Volkes rück te ihn nicht nur in die Nähe des zaristischen Ministers Witte, sondern deutet seinen zukünftigen Weg als Führer der Partei der russischen liberalen Bourgeoisie und Grundbesitzer, der Konstitutionellen Demokraten (Kadetten) bereits an. Trotzdem konnte er noch einige Zeit mit der russischen Sozialdemokratie zusammenarbeiten und sogar das Gründungsmanifest der Sozialdemokratischen Arbeiterpartei Rußlands (SDAPR) verfassen. Sie wurde am 1. (13.)

Nikolaion (Danielson), Die Volkswirtschaft in Rußland nach der Bauernemanzipation, deutsche Ausgabe München 1899

45 Ebd., S. 511

46 Ebd., S. 399

47 Dazu D. Geyer, a.a.O., S. $26-35$

48 zitiert nach Geyer, ebd., S. 28

$49 \quad$ Ebd., S. 32/3 
März 1898 von neun Vertretern politischer Zirkel auf Initiative des Allgemeinen Jüdischen Arbeiterbundes in Rußland und Polen ins Leben gerufen, doch spielte zunächst keine praktische Rolle, zumal die Mehrzahl der Delegierten und Beteiligten bereits zehn Tage später durch eine Verhaftungswelle von der Ochrana unter der Leitung des Moskauer Polizeichefs Zubatows festgenommen wurden (50).

Standen die ,illegalen ${ }^{66}$ und "legalen ${ }^{64}$ Marxisten auch in einer Front gegen die Volkstümler und postulierten die Notwendigkeit einer kapitalistischen Entwicklung Rußlands, so gab es zwischen diesen beiden Gruppen doch zunehmend Differenzen, die sich wesentlich an der politischen Haltung zu Bourgeoisie und Proletariat festmachten. Während die legalen Marxisten an einem Bündnis aller demokratischen Kräfte gegen die Autokratie interessiert waren, so kam die Gruppe um Plechanow auf empirischem Wege allmählich von dieser, eine ganze Zeit lang vertretenen Position ab und bekannte sich, wie oben ausgeführt, moralisch und widersprüchlich zur Arbeiterklasse und geriet so in einen partiellen Gegensatz zu der legalen Fraktion.

Diese Zwischenposition, samt deren immanenten Widersprüchlichkeit, war Ausdruck der unterentwickelten Klassen- und Kapitalverhältnisse im damaligen Rußland, in dem die Arbeiterklasse zwar eine Reihe von militanten Kämpfen bestritt, die zwischen 1896 und 1898 in fast allen Industriezentren ausbrachen (51), aber aufgrund der objektiven Beschränkung noch nicht die sozialistischen Formen der Vergesellschaftung freisetzen konnte. Nur aufgrund dieser spezifischen gesellschaftlichen Situation war es möglich, Bourgeoisie und Proletariat in einem ,Volksstaat" oder einer ,Volksproduktion" versöhnen zu wollen bzw. glauben zu können, daß das Proletariat durch ,Einsicht in die historische Notwendigkeit" die Aufgaben der Bourgeoisie im Rahmen der bürgerlichen Gesellschaft an deren Stelle erledigen könne.

Aber diese nuancierten Differenzen erlaubten es Plechanow z. B. an der deutschen Revisionismusdebat te mit Beiträgen in der ,Neuen Zeit ${ }^{66}$ teilzunehmen und philosophische Schlachten mit Bernstein auszufechten, zumal der Bernsteinsche Reformismus begierig von der Fraktion der legalen Marxisten als von autorisierter Seite kommende Bestätigung ihrer Theorie aufgenommen wurde, daß gesellschaftlicher Fortschritt evolutionär und im Rahmen der bürgerlichen Gesellschaft zu verwirklichen sei, und sich in Rußland gegen die „orthodoxen“ Marxisten durchzusetzen begann (52). Bernsteins Kritik der Zusammenbruchstheorie der II. Internationale, dem er seinen Evolutionsbegriff entgegensetzte und sein Versuch der Vereinigung des Materialismus mit dem Kantianismus (53) rief nicht nur in der deut-

50 Vgl, Geyer, ebd., S. 108 und Martow, a.a.O., S. 33 ff

51 Vgl. Martow, a.a.O., S. 22-25

52 Vgl. Geyer, a.a.O., S. $139-160$

53 Vgl. dazu die Artikelserie Bernsteins, Probleme des Sozialismus, Neue Zeit, 1896-98, die unter dem Titel: Zur Geschichte und Theorie des Sozialismus, Berlin/Bern 1901 als Broschüre veröffentlicht wurde und die überarbeitete Fassung: Die Voraussetzungen des Sozialismus und diy Aufgaben der Sozialdemokratio, Stuttgart 1899. Zur Darstellung und Einschätzung der Bernstein'schen Theorie siehe: Pierre Angel, Eduard Bernstein et l'évolution du socialisme allemand, Paris 1961, Bo Gustafsson, Marxismus und Revisionismus - Eduard Bernsteins Kritik am Marxismus und ihre ideengeschichtlichen Voraussetzungen, 2 Bände, Frankfurt 1972 
schen, sondern auch in der russischen Sozialdemokratie Widerspruch hervor. Plechanow richtete sich mit seiner Polemik (54) vornehmlich gegen die philosophische Begründung des Reformismus, den Versuch der Aussöhnung des Idealismus mit dem Materialismus. Er erwies sich in dieser Debatte als philosophischer Verfechter der Orthodoxie der II. Internationale, als ein russischer Kautsky, dessen politisches Schicksal er auch teilen mußte. Plechanows deterministisches Etappenmodell der gesellschaftlichen Entwicklung, das er in Anlehnung an die Marxismus-Interpretation der deutschen und österreichischen Sozialdemokratie und damit der II. Internationale ebenfalls für Rußland anwandte, dessen wesentliches Kernstück der Versuch der realpolitischen Integration der Arbeiterklasse in den Rahmen der bürgerlich-demokratischen Gesellschaft bei gleichzeitiger Beibehaltung eines utopischen Endzieles Sozialismus war, mußte in dem Moment in Frage gestellt werden, wo die Arbeiterklasse begann, über diesen gesetzten Rahmen hinauszuspringen und sozialistische Tendenzen, die sich aus ihrer objektiven Stellung in der kapitalistischen Produktionsweise und Gesellschaft ergeben, freisetzte. Ist dieser Punkt durch den Fortschritt der Kapitalakkumulation oder die Zuspitzung gesellschaftlicher Widersprüche im nationalen und internationalen Maßstab erreicht, so mußte entweder eine Revision der sich gegen diese Richtung stemmende Ideologie eintreten, oder die im Stadium unterentwickelter Klassenverhältnisse und gesellschaftlicher Widerspriiche ehemals progressive Ideologie mußte in puren Konservativismus umschlagen und ihre Vertreter zu Parteigängern der Bourgeoisie der jeweiligen Länder werden lassen.

Plechanow, der schon früher betont hatte, daß ,der Charakter des natürlichen Milieus... den des sozialen Milieus (bestimmt)" (55), konnte sich eine Entfaltung gesellschaftlichen Fortschrittes, den er mit Kapitalismus identisch setzte, nur als Folge einer kulturellen und ökonomischen „Europäisierung“ des babarischen Rußlands denken. Auch hier steht er voll in der Tradition der II. Internationale und deren Selbstbewußtsein, das sogar mit Hilfe imperialistischer Kolonialpolitik, die unter diesem Gesichtspunkt einen sozialistischen Charakter tragen sollte (56), durchgesetzt werden sollte. Auf dem Internationalen Sozialistenkongreß in Zürich 1893 unterstützte Plechanow den deutschen Antrag einer Resolution gegen Militärstreiks im Kriegsfalle mit dem Argument der Notwendigkeit der Verteidigung der „Zivilisation“ gegen den „Hort der Grausamkeit und Kulturfeindschaft" als revolu-

54 Siehe G. W. Plechanow, Bernstein und der Materialismus, in: Neue Zeit, Jg. XVI, Bd. 2, S. $544-55$ ders., Konrad Schmidt gegeri Karl Marx und Friedrich Engels, ebd., Jg. XVII, Bd. 1, S. $133-45$

ders., Materialismus oder Kantianismus, ebd., Jg. XVII, Bd. 1, S. 589-96 und 626-32 ders., Wofür sollen wir ihm dankbar sein? Offener Brief an Karl Kautsky, in: Beilage der Sächsischen Arbeiterzeitung, Dresden, Nr. 253-55, 2.10. und 3.11.1898

55 Ders, Beiträge zur Geschichte des Materialismus, a.a.O., S. 169 siehe auch: Zur Frage ..., a.a.O., S. 148 , S. 269 ff, S. 303 ff

56 Vgl dazu Kurt Mandelbaum, Sozialdemokratie und Imperialismus, in: ders., Sozialdemokratie und Leninismus, a.a.O., S. 3-48 
tionäres Prinzip (57), und stimmte gegen einen holländischen Antrag zur Kriegsdienstverweigerung. Dieses hier schon angelegte Prinzip der Vaterlandsverteidigung, das sich in diesem Fall gegen die russische Autokratie richtete, behielt Plechanow dann auch im imperialistischen I. Weltkrieg bei, nur daß er jetzt das dem Zarismus durch seine ökonomische Abhängigkeit aufgezwungene Bündnis mit der Entente als das Bündnis der Werktätigen Rußlands, mit denen der westlichen Demokratien interpretierte, die gemeinsam gegen das politisch reaktionäre und aggressive deutsche Kaiserreich zu kämpfen hätten und ein Sieg der westlichen Demokratien auch zum Sturz der russischen Autokratie führen müsse und Rußland so den Weg zu einer bürgerlichen Demokratie öffnen würde (58). Dieses Eintreten für eine bürgerliche Revolution, alle rdings in Abhängigkeit vom ausländischen Kapitalismus, mußte ihn folgerichtig in einen diametralen Gegensatz zur Oktoberrevolution führen.

In dieser Entwicklung zeigte sich auch für Rußland der in revolutionären Situationen konservative, teilweise sogar reaktionäre Charakter der sozialdemokratischen Integrationsideologie. Sie mußte aber in Rußland praktisch scheitern, weil hier, im Gegensatz zu den entwickelten Nationen, auch ein teilweiser gesellschaftlicher Fortschritt nur durch eine Überwindung des Einflusses des ausländischen Kapitals, der Autokratie und des mit ihr liierten nationalen Kapitals erreicht werden konnte. Die besonderen Formen der Marxismusrezeptionen, wie sie in Rußland von den Narodniki, den legalen Marxisten und den Sozialdemokraten vorgenommen wurden, zeigen also sämtlichst deutliche Spuren der beschränkten und widersprüchlichen sozio-ökonomischen Entwicklung Rußlands, die zum einen zwar eine ausweglos erscheinende Krisensituation und die Empfänglichkeit der Intelligenz für radikale Theorien produzierte, zum anderen aber noch nicht die materiellen und klassenmäßigen Vorbedingungen zu ihrer Lösung geschaffen hatte, so daß der Marxismus als eine wissenschaftliche Interpretation der Möglichkeiten gesellschaftlichen Fortschritts, letztendlich seines wesentlichen Inhaltes beraubt wurde und jeder Fraktion zur Rechtfertigung ihrer besonderen Interessen dienen sollte. Den Narodniki als Beleg für die Amoralität des Kapitalismus, den legalen Marxisten als Ideologie der Notwendigkeit einer unbeschränkten Herrschaft der Bourgeoisie, die sie der Autokratie gegenüberstellten. Die Sozialdemokraten konnten durch ihre Marxismusinterpretation sowohl mit der sentimentalen Ideologie eines Agrarsozialismus der Volkstümler, wie auch mit der puren Kapitalismusapologie der legalen Marxisten brechen. Obwohl auch die Sozialdemokraten durch die Übernahme der Etappentheorie der II. Internationale von der Notwendigkeit und der Unumgänglichkeit der Herrschaft des Kapitalismus ausgingen, stellten sie sich doch zumindest moralisch auf die Seite des Proletariats, indem sie den Kapitalismus als notwendiges Übergangsstadium zum Sozialismus interpretierten. Aber dieses modellhafte Schema mußte zunächst zu einer völligen realpolitischen Unterstützung der kapitalistischen Tendenzen führen, denen die aktuellen und historischen Interessen der Arbeiterklasse unter dem Hin-

57 Vgl. Protokoll des Internationalen Arbeiterkongresses in der Tonhalle Zürich vom 6. -12.8 .1893 , Zürich 1894 , S. $20-23$ und $29 \mathrm{f}$

58 Dazu S. H. Baron, Plekhanov, the Father of Russian Marxism, a.a.O., S. $327 \mathrm{f}$ 
weis auf das sozialistische Endziel untergeordnet werden mußten. Da für sie das einzige Vermittlungsglied von Zarismus und Sozialismus auf nationaler Ebene die möglichst weitgehende Entfaltung der kapitalistischen Produktionsverhältnisse war, ist damit die Gefahr angedeutet, im Namen der Arbeiterklasse letztlich bürgerliche Politik zu betreiben.

Diese Widersprüchlichkeiten der Marxismusrezeption und der politischen Bestimmung der russischen Sozialdemokratie bieten die ideelle Grundlage dafür, daß sich unter dem Druck und der Tendenzen der Klassenkämpfe Modifikationen und Fraktionierungen ergeben können, die entweder Impulse aus diesen Kämpfen in sich aufnehmen oder andersherum in Zeiten relativer Stagnation der Kämpfe wiederum Elemente und Traditionen substitutionalistischer Politik verstärken und so unter bestimmten gesellschaftlichen Verhältnissen die in diesem Konzept angelegten Tendenzen zur Realität werden lassen.

Das methodische Problem dabei besteht darin, zu erklären, wie die Möglichkeit des Aufhebens oder des verstärkten Anknüpfens bestimmter Traditionen mit der Entwicklung und Veränderung der gesellschaftlichen Grundlagen vermittelt ist, um sowohl Analogieschlüsse, die sich auf der Ebene der Erscheinungsformen mit dem Konstatieren gewisser Ähnlichkeiten begnügen, wie auch den Ansatz zu vermeiden, die konkrete geschichtliche Entwicklung aus der immanenten Logik bestimmter ideologischer Positionen erklären zu glauben können. Ferner gilt es dem Dilemma einer gegensätzlichen Vorgehensweise zu entgehen, die in abstrakter Ablehnung der ideengeschichtlichen Untersuchung, plötzlich mit ,Brüchen' in der revolutionären Kontinuität konfrontiert ist, die dann nur noch mit kategorialen Vehikeln wie ,Verrat' etc. zu erklären sind (59).

Genausowenig, wie damit eine Interpretation des Verhaltens der Sozialdemokratie im ersten Weltkrieg möglich ist, kann so der Prozeß der Stalinisierung der Sowjetunion erklärt werden.

Wir werden im folgenden versuchen, die Widersprüchlichkeiten der klassenpolitischen Orientierung der russischen Sozialdemokratie am Beispiel des Lenin'schen Organisationskonzeptes herauszuarbeiten, weil dieses Konzept trotz aller Modifikationen gewissermaßen die Bewegungsform darstellte, in der sich die Entwicklung der politischen Inhalte vollzog und ihnen damit auch teilweise das Gepräge gab.

\section{Die Herausbildung und Entwicklung des leninistischen Organisationskonzep- tes}

Die Einschätzung der Lenin'schen Kapitalismus- und Klassenanalyse, der Taktikbestimmung der Sozialdemokratie, als deren synthetischer Ausdruck die daraus abgeleitete Organisationsform und ihr Verhältnis zur realen Klassenbewegung zu begrei-

59 Die ausfuhrliche Entfaltung dieses in der vorliegenden Arbeit angedeuteten Versuchs ist gegeben bei: Ulf Wolter, Grundlagen des Stalinismus, Die Entwicklung des Marxismus von einer Wissenschaft zur Ideologie, Berlin 1975 
fen ist, hat demnach die Skizzierung der russischen Produktionsverhältnisse (60), die Entstehungsgeschichte der revolutionären Bewegung in Rußland und der Ideologie der II. Internationale zur Voraussetzung.

Ein Versuch einer Leninismusinterpretation, der positive oder negative Fixierungen an einzelnen Aussagen Lenins vermeiden will, muß die historische Bedingtheit der einzelnen Entwicklungsschritte der Positionen Lenins berücksichtigen, um feststellen zu können, inwiefern er in seinen Ausführungen den Gang der tatsächlichen Verhältnisse wissenschaftlich interpretieren kann und zu angemessenen politischen Schlußfolgerungen kommt, oder aber ob hier Ideologisierungen, also Bewußtseinsverkehrungen über die gesellschaftliche Realität, zu finden sind.

Lenin entwickelt seine wissenschaftlichen Grundlagen und Anschauungen vor allem in der Auseinandersetzung mit den Volkstümlern über die Einschätzung des Charakters der russischen Produktionsverhältnisse und die sich daraus ergebenden gesellschaftlichen und politischen Perspektiven. Diese Debatte wird mit der Fraktion der ,legalen Marxisten" weitergeführt, obwohl sie bis zur organisatorischen Festigung der Liberalen primär als ergänzende und nicht als kontroverse verstanden wird (61).

In diesen Diskussionen festigt sich die, in anderem Zusammenhang bereits ausführlich dargestelite, Marxismusrezeption Lenins, in der, über die Vermittlung Plechanows, die wesentlichen Grundlagen der Marxismusrezeption der deutschen Sozialdemokratie reproduziert werden, die Lenin für seine Analyse Rußlands anzuwenden versucht, wobei im Hinblick auf die Ausarbeitung seiner Organisationskonzeption zwei wesentliche Momente noch einmal kurz zu betonen sind. Zum einen Lenins mangelndes Verständnis über Bewußtseinsformen, wenn er die Genesis theoretischer Abstraktionen als Produkt aparten Denkens interpretiert, als geniale Idee und Hypothese und nicht als vermittelten ideellen Reflex der tatsächlichen Verhältnisse.

Wir sehen hier den theoretischen Kern einer Konstruktion, die eine prinzipielle Differenz des wissenschaftlichen Sozialismus und seiner Träger zur spontanen Arbeiterbewegung behauptet, da die Entwicklung der Wissenschaft selbst nicht aus den materiellen Verhältnissen erklärt wird, sondern als autonomes Verstandesprodukt genialer Intellektueller, dessen Aussimilation nur auf dem Weg theoretischer Arbeit gelingen kann und nicht das Produkt der Kämpfe der Arbeiterklasse und der in ihnen stattfindenden Freisetzung der sozialistischen Tendenzen der Vergesellschaftung der Arbeit von ihren kapitalistischen Formen sein könne, woraus sich

60 Da wir hier im Wesentlichen auf das Organisationskonzept eingehen, verweisen wir in Bezug auf die anderen Aspekte auf unseren Aufsatz: Halbheiten in der Überwindung des Leninismus, Zur Leninkritik des PKA, in: Probleme des Klassenkampfs, Nr. 11/12 sowie auf die bereits genannten anderen Arbeiten.

$61 \mathrm{VgL}$ dazu etwa die Einschätzung Lenins über die Kritik von P. Struve an den Volkstümlern, Der ökonomische Inhalt der Volkstümlerrichtung, Lenin Werke (LW), Berlin DDR, Bd. 1, S. $343 \mathrm{ff}$, in dem er Struves Kritik zu ergänzen bemüht ist und ihm vorhält, ,,daß er diese Theorie (des Marxismus, U. W.) nicht mit aller Strenge durchgehalten hat". (527) 
konsequent ein bestimmtes Verhältnis der in der Partei organisierten Träger des wissenschaftlichen Sozialismus zur Arbeiterbewegung ergeben muß. Eine derartige Auffassung wird noch dadurch bestärkt, daß Lenin die Dialektik von Form und Inhalt mit der von Basis und Überbau identisch setzt und damit faktisch, durch die Vermischung der Kategorien von Allgemeinem und Besonderem, eine Negation gerade dieser Form-Inhalt Dialektik vornimmt, indem er sie aus der Basis der kapitalistischen Produktionsverhältnisse selbst zu eliminieren versucht, wenn er die kapitalistischen Formen der Vergesellschaftung der Arbeit mit den sozialistischen Formen gleichzusetzen versucht.

Die Verkennung des Doppelcharakters der Gesellschaftlichkeit der Arbeit im Kapitalismus führt ihn zu der Position, daß es im Wesentlichen darum gehe, den bislang noch reaktionären Überbau der bereits tendenziell vergesellschafteten, $d . h$. für Lenin tendenziell sozialistischen, Basis anzupassen. Es gelte demnach die Kapitalisierung der Gesellschaft zu unterstïtzen. Solange die kapitalistische Vergesellschaftung der Arbeit immer noch einen historischen Fortschritt gegenüber den teilweise vorkapitalistischen Verhältnissen Rußlands bedeutete, konnten die Konsequenzen dieser Politik nicht restlos klar werden, obwohl sie ihren deutlichen Niederschlag in den fabrikmäßigen Formen der Organisierung der Partei finden. In aller Schärfe zeigen sie sich erst in dem Moment, wo beim Aufbau des Sozialismus versucht wird, Formen der kapitalistischen Organisierung der Arbeit zu übernehmen.

Zum anderen muß darauf hingewiesen werden, daß Lenin auf Grund seines Wissenschaftsverständnisses versucht, den Marxismus als Hypothese zur Erklärung kapitalistischer Gesellschaften auf Rußland anzuwenden und zu verifizieren. So kommt er bereits 1899 in seiner Analyse der Entwicklung des Kapitalismus in Rußland zu dem Schluß, daß bereits über die Hälfte der Gesamtbevölkerung von 125,6 Mio., nämlich 63,7 Mio. Proletarier und Halbproletarier sind (62), Rußland demnach ein, wenn auch unterentwickeltes, kapitalistisches Land sei. Demgegenüber hat die Analyse der russischen Produktionsverhältnisse gezeigt, daß Rußland um die Jahrhundertwende weit davon entfernt war, ein durchkapitalisiertes Land zu sein und sogar noch 1914 der Prozeß der ursprïnglichen Akkumulation noch nicht abgeschlossen war, dagegen vielmehr die Parallelität von ursprünglicher und kapitalistischer Akkumulation und vorkapitalistischen Produktionsformen Kennzeichen dieser Gesellschaft war.

Obwohl Lenin beständig von der quantitativen Dominanz des Kapitalverhältnisses in Rußland ausgeht, nimmt er diese Einschätzung jedoch nicht zur Basis der Bestimmung der politischen Aufgaben der Sozialdemokratie, denn nach dieser These würde für Rußland zumindest tendenziell die sozialistische Revolution auf der Tagesordnung stehen. Die taktische Frage für die Sozialdemokratie wäre in diesem Fall, einen Zusammenschluß der verschiedenen Fraktionen der Arbeiterklasse in einer Aktionseinheit zu erreichen und ein Übergangsprogramm auszuarbeiten, das eine organische Verbindung der verschiedenen Kampfformen des Proletariats und 
eine Beschleunigung des Übergangs von demokratischem in sozialistischen Kampf bewirken könne, während die Bündnisfrage, also die des politschen Zusammengehens verschiedener Klassen, in einem Land mit entfaltetem Kapitalverhältnis nur von untergeordneter Bedeutung ist.

Lenin betont aber bis 1917, und auch da ist seine Einschätzung noch ambivalent, daß in Rußland lediglich eine bürgerliche Revolution das nächste Ziel der gesellschaftlichen Entwicklung sein kann, die ihren Inhalt in der Abschaffung der Selbstherrschaft und der Errichtung einer bürgerlichen Republik findet.

Innerhalb dieses Rahmens werden sich die kapitalistischen Produktionsverhältnisse entfalten, die Arbeit vergesellschaften und damit die materielle Basis für eine sozialistische Transformation der Gesellschaft gelegt, die dann das Werk der im Kapitalismus notwendig entstehenden Arbeiterklasse sei. Im Rahmen der Republik sieht Lenin die Möglichkeiten der breiten, weil legalen Einflußmöglichkeiten der Sozialdemokratie auf die Arbeiterklasse als einen entscheidenden Punkt an, weil dieser die politischen Grundlagen und Dimensionen ihres Kampfes erst klargemacht werden müßten und damit erst die Möglichkeit des Umschlags der ökonomischen in den politischen, d. h. unter diesen Bedingungen, sozialistischen Kampf möglich sei. Solange aber diese gesellschaftlichen Bedingungen nicht erkämpft sind, ist für Lenin jegliches Gerede von der Möglichkeit einer über den Rahmen der bürgerlichen Revolution hinausgehenden gesellschaftlichen Veränderung leeres Geschwätz, Utopie, Anarchismus oder reaktionär kleinbürgerliche Illusion. Es fällt auf, daß dieses Etappenmodell der politischen Aufgaben in direktem Gegensatz zu seinem Etappenmodell der Entwicklung des Kapitalismus in Rußland steht und es wird deutlich, daß er die taktische Bestimmung der Hauptaufgaben der Sozialdemokratie, nämlich Sturz der Selbstherrschaft, in Anlehnung an die Position der Narodniki formuliert.

Klassenanalyse und Taktik stehen sich unvermittelt gegenüber. Während er in seiner Klassenanalyse zu dem Resultat der Dominanz kapitalistischer Verhältnisse kommt, geht er in seiner Taktik immer nur vom bürgerlichen Charakter der kommenden Revolution aus. Den inneren Zusammenhang, daß die Aufgaben der bürgerlichen Revolution in Rußland nur durch eine sozialistische Revolution erfüllt werden können, reproduziert Lenin so als äußerlichen, indem sich die beiden Bestimmungen direkt und sich gegenseitig ausschließend gegenüberstehen. Diese Widersprüchlichkeit deutet an, daß Lenin selbst zum Gefangenen des ideologischen Charakters seiner Gesellschaftsanalyse geworden ist.

Die Bestimmung der politischen Aufgaben der Sozialdemokratie und deren Organisationskonzept, wurden wesentlich im Laufe der Polemiken mit der ,ökonomistischen" Fraktion und später den Menschewiki, teilweise auch in der Auseinandersetzung mit der linken Fraktion von Leo Trotzki und Rosa Luxemburg (63)

63 Vgl dazu die Rußlandschriften Rosa Luxemburgs in: Gesammelte Werke, Berlin 1972 , Bd. 1/2, sowie die verschiedenen Beiträge Trotzkis, wie die in dem Band: Schriften zur revolutionären Organisation, Hamburg 1972, zusammengestellten, ferner Rapport de la Délégation sibérienne, Paris 1971 und verschiedene in der Neuen Zeit erschienene Beiträge. 
herausgearbeitet. Weitere Modifikationen ergeben sich im Verlaufe der Fraktionskämpfe innerhalb der russischen und der internationalen Sozialdemokratie. In den grundlegenden Zügen hatte Lenin aber seine Auffassungen, die die Basis für seine zukünftige theoretische und politische Arbeit abgeben, bereits bis 1902 entwickelt und lehnt sich auch später deutlich an das in dieser Periode geprägte Wissenschaftsverständnis und den sich daraus ergebenden politischen und organisatorischen Positionen an. Trotz der unter dem Druck der politischen Entwicklung und der sich radikalisierenden Klassenkämpfe häufigen Modifikationen und Revisionen, die Lenin an seinen Positionen vornehmen konnte, bewegt er sich auf theoretischem Gebiet immer im Rahmen dieses Verständnisses. Deshalb kommt dieser Periode der Herausbildung des Leninismus eine entscheidende Bedeutung zu, weil hier dessen theoretische und organisatorische Grundlagen gelegt werden, zumal sich die stalinistische Leninismusinterpretation, also der offizielle Marxismus-Leninismus, in den 20er Jahren deutlich gerade an die frühen Formulierungen Lenins anlehnt, obwohl er selber bestimmte Positionen teilweise überwunden, teilweise modifiziert hatte, wenngleich auch hinzugefügt werden muß, daß Lenin aber niemals zu einer radikalen Aufhebung der Widersprïchlichkeiten in seiner theoretischen, politischen und organisatorischen Konzeption gelangen konnte, sondern lediglich zu einer ungefähren Anpassung dieser Konzeption an die reale Bewegung.

Der Analyse des Leninschen Konzeptes des Aufbaus und der Aufgabenstellung der Partei komm $\grave{t}$ bei einer Einschätzung sowohl seines unmittelbar historischen politischen Wirkens zentrale Bedeutung bei, wie auch in der Einschätzung der geschichtlichen Rolle, die der Leninismus, bzw. Marxismus-Leninismus, als Kanonisierung einer bestimmten Lenininterpretation, in der Geschichte der Arbeiterbewegung gespielt hat und immer noch spielt. Denn dieses Organisationakonzept wat gewissemaßen die Bewegungsform, in der sich relativ beliebige politische Inhalte, wir denken bloß an den politischen Zick-Zack-Kurs der III. Internationale, prinzipiell gegenüber der Klasse rechtfertigen ließen und trotzdem zu keiner grundsätzlichen Anderung der Beziehungen von Partei und Klasse führte, sondern im Gegenteil sogar noch den Hegemonialanspruch der Partei gegenüber der Klasse in dem Maße festigte, wie die, der kommunistischen Fraktion der Arbeiterklasse aufgezwungene, Taktik zu Niederlagen des gesamten Proletariats von historischem Ausmaß beigetragen hat und damit beständig Eigeninitiative, Kampfkraft und damit Widerstandsvermögen gegen die Dominanz der Funktionäre und der Parteibürokratie unterhöhlte.

Lenin sieht als Ergebnis der Auseinandersetzung mit den Volkstümlern sowohl eine Spaltung der sozialistischen von der kleinbürgerlich-reaktionären Fraktion der Intelligenz, wie eine genügende theoretische Fundierung der sozialdemokratischen Fraktion der Intelligenz, deren Ergebnisse es jetzt in der Praxis umzusetzen gelte. "Die theoretischen Anschauungen der Sozialdemokratie scheinen jetzt (Ende 1897) in ihren Haupt- und Grundzügen genügend geklärt zu sein. Von der praktischen Seite des Sozialdemokratismus, von seinem politischen Programm, von 
seinen Arbeitsmethoden und seiner Taktik läßt sich das nicht behaupten" (64). Und weiter: „Die praktische Tätigkeit der Sozialdemokraten ist bekanntlich darauf gerichtet, den Klassenkampf des Proletariats zu leiten und in seinen beiden Formen zu organisieren: den sozialistischen $(\ldots)$ und den demokratischen $(\ldots)^{66}(65)$. Diese Formulierung wurde im Zusammenhang mit seinem Versuch der Klassenanalyse Rußlands und der darin behaupteten Dominanz des Kapitalverhältnisses gebraucht.

Nachdem Lenin aber seine zur eigenen Klassenanalyse gegensätzliche Taktik unter dem Eindruck der realen Kräfteverhältnisse präzisiert hat, nach der es zunächst im Bündnis mit Teilen der Bourgeoisie und der Bauern den Sturz der Autokratie zu bewirken gelte, um damit die Bedingungen für eine freie Entfaltung des Kapitalismus und der Industriealisierung Rußlands zu schaffen, muß er auch seine Definition des Inhalts des Klassenkampfes, und damit auch die Aufgabenstellung für die revolutionäre Partei ändern, indem in dieser Kampfetappe in seiner Konzeption die sozialistischen Elemente zunächst keine weitere als propagandistische Bedeutung mehr haben. „Der Klassenkampf des Proletariats besteht aus dem ökonomischen Kampf (Kampf gegen einzelne Kapitalisten oder gegen einzelne Kapitalistengruppen für die Verbesserung der Lage der Arbeiter) und dem politischen Kampf (Kampf gegen die Regierung für die Erweiterung der Rechte des Volkes, d. h. für Demokratie, sowie für die Erweiterung der politischen Macht des Proletariats) ${ }^{66}(66)$. Da nach Lenins taktischer Bestimmung die Herstellung einer kapitalistischen Gesellschaft im politischen Bündnis mit den ebenfalls an diesem Ziel interessierten Klassen oder Klassenfraktionen die nächste Aufgabe ist, läßt er die sozialistischen Tendenzen des Klassenkampfs der Arbeiter für diese Etappe außer Acht. Es ist die Aufgabe der Partei, die sozialistischen Ideale zu bewahren, während es die unmittelbare politische Aufgabe sei, den demokratischen Kampf zu führen. Die Aufgabe der Sozialdemokratie ist es, ,beide (Kampfformen, die Verf.) zum einheitlichen Klassenkampf des Proletariats zu verbinden ${ }^{66}(67)$, ihn zu organisieren und anzuleiten. Die Transformation des beschränkten ökonomischen in den Klassenkampf des Proletariats, der lediglich als politischer mit demokratischem Inhalt gefaßt ist, wird für Lenin nur durch die Vermittlung der revolutionären Intelligenz möglich. „Die Aufgabe der Sozialdemokratie besteht eben darin, durch Organisierung der Arbeiter, durch Propaganda und Agitation unter ihnen ihren spontanen Kampf gegen die Unterdrücker in einen Kampf der ganzen Klasse, in den Kampf einer bestimmten politischen Partei für bestimmte politische und sozialistische Ideale zu verwandeln" (68). Da nach Lenins Auffassung des Primats der Politik der Klassenkampf lediglich ein politischer ist, wobei er eine mechanische Verbindung anstelle der dialektischen im Verhältnis vom ökonomischen zum politischen Kampf setzt, nach der der ökonomische Kampf lediglich die Funktion hat, das Proletariat

Ebd.

Ders. Unser Programm, LW 4, S. 206

Ebd., S. 20 ?

68 Ders. Unseren nächsten Aufgaben, LW 4, S. 210 (Hervorhebung im Original) 
elementar zusammenzuschließen und so die organisatorischen Grundlagen dafür zu schaffen, daß die politische Qualität des Kampfes, die die Partei repräsentiert, diesem elementaren Zusammenschluß klargemacht werden kann. Da aber das Proletariat seiner Meinung nach selber nicht in der Lage sei, die politischen Ziele seines Kampfes zu formulieren, weil sie nur durch die moderne Wissenschaft bestimmt werden können, besteht sowohl die Notwendigkeit, eine von der Klasse strikt getrennte Organisation von Revolutionären zu schaffen, die die sozialistischen Ideale verkörpert und die politischen Dimensionen des Kampfes klarmacht, wie andererseits diese Organisation von Berufsrevolutionären mit der elementaren Bewegung zu verschmelzen. „Die Sozialdemokratie reduziërt sich nicht auf einfachen Dienst an der Arbeiterbewegung: sie ist die ,Vereinigung von Sozialismus und Arbeiterbewegung (Kautsky); es ist ihre Aufgabe, in die spontane Arbeiterbewegung bestimmte sozialistische Ideale hineinzutragen, sie mit sozialistischen Überzeugungen, die auf dem Niveau der modernen Wissenschaft stehen müssen, zu verbinden ..., mit einem Wort diese spontane Bewegung mit der Tätigkeit der revolutionären Partei zu einem unauflöslichen Ganzen zu verschmelzen" (69). Da Lenin aber weder die Genesis des wissenschaftlichen Sozialismus aus den materiellen Verhältnissen erklären kann, noch die Beschränkungen des Klassenbewußtseins selbst als Reflex der unterentwickelten gesellschaftlichen Verhältnisse und der konjunkturell unterschiedlichen Reproduktionsbedingungen des Kapitals sieht, stellt sich für ihn der an sich richtige Anspruch des ,Verschmelzens ${ }^{6}$ als die Verbindung zweier prinzipiell unabhängiger Bewegungen dar. Das Anknüpfen an den ökonomischen Kampf dient demnach lediglich zur Schaffung eines Vertrauensverhältnisses zur Arbeiterklasse und knüpft nicht an dessen innerer Dynamik an, die einen Umschlag in den politischen Kampf impliziert. Demzufolge ist für ihn sozialdemokratische Tätigkeit mit „Organisation und Leitung des proletarischen Klassenkampfs" (70) identisch. Um diese Aufgabe erfüllen zu können, muß aber das Stadium der regionalen Handwerkelei und des Zirkelwesens überwunden werden, wozu die Herausgabe eines Zentralorgans als eine Stufe des Parteiaufbaus ein wesentlicher Schritt ist. ,Der ökonomische Kampf, der nicht durch ein Zentralorgan zusammengefaßt wird, kann nicht zum Klassenkampf des gesamten Proletariats werden. Die Führung des politischen Kampfes ist unmöglich, wenn nicht die ganze Partei zu allen Fragen der Politik Stellung nimmt und den Kampf in seinen einzelnen Erscheinungsformen lenkt" $(71)$. Es sind daher „eine Verbesserung der revolutionären Organisation und Disziplin, eine Vervollkommung der konspirativen Technik ... dringend notwendig" (72). Die Bildung einer zentralisierten Partei ist erforderlich, weil nur sie es ermöglicht, „die Prinzipien der Arbeitsteilung und der Kräfteersparnis systematisch durchzuführen, (...) um ... einen systematischen Kampf gegen die Regierung führen zu können" (73). Dement-

Ebd., S. 211

70 Ebd., S. 212 (Hervorhebung im Original)

71 Ebd., S. 213 (Hervorhebung im Original)

72 Ders., Eine dringende Frage, LW 4, S. 215

73 Ebd., S. 216 (Hervorhebung U. W.) 
sprechend formuliert er im Leitartikel der Nr. 1 der Iskra, „daß es die nächste politische Aufgabe der russischen Arbeiterpartei sein muß, die Selbstherrschaft zu stürzen, politische Freiheit zu erobern ${ }^{66}(74)$.

In der Polemik gegen den legalen Marxismus (75) und vor allem gegen die ,ökonomistische ${ }^{6}$ Fraktion der Sozialdemokratischen Partei, der sowohl dieser Artikel, wie auch die an diese Gedankengänge anschließenden Arbeiten „Womit beginnen“, „Was tun“ und „Brief an einen Genosssen über unsere organisatorischen Aufgaben" dienen, stellt Lenin seine Auffassungen über das Verhältnis von Partei und Klasse, sowie das Konzept des Organisationsaufbaus ausführlich dar und legt damit den Grundstein für die bolschewistische Fraktion innerhalb der russischen Sozialdemokratie und die sich aus ihr entwickelnde Partei.

In dem Lenin'schen Organisationsplan sind zwei Elemente zu unterscheiden. Das erste ist das variable, von den politischen Bedingungen des Landes abhängige Element, also das der weitgehenden Konspiration unter den Bedingungen der völligen politischen Unfreiheit. Das zweite Element dagegen ist prinzipieller, also unveränderlicher Natur und ergibt sich aus Lenins Anschauungen über die Genesis des proletarischen Klassenbewußtseins und theoretischer Abstraktionen, die er nach wie vor als voneinander unabhängige Bewegungen faßt (76), diese Trennung sogar noch polemisch gegen die ökonomistische Fraktion zuspitzt, die das eindeutige Primat der sozialdemokratischen Arbeit auf den gewerkschaftlichen Kampf legen will. Ihnen hält Lenin vor, daß die Arbeiterklasse von sich aus zwar eine spontane Bewegung gegen die Übergriffe des einzelnen Unternehmers hervorzubringen in der Lage ist, daß sie aber die Grenzen dieses Trade-Unionismus selbst nicht überwinden kann. Dies ist lediglich durch „,tiefe wissenschaftliche Einsicht ${ }^{66}$ möglich, deren Träger nur die bürgerliche revolutionäre Intelligenz, bzw, die sich in der Partei von Berufsrevolutionären auf dieses Bewußtsein heraufgearbeitete Schicht der Arbeiterintelligenz sein kann. Da Lenin aber die Einsicht in die tatsächlichen Verhältnisse nicht als ideelles Produkt dieser Verhältnisse begreift, kann er folglich auch keine materialistische Bestimmung illusionärer Bewußtseinsformen vornehmen, die ihm als, Verrat" (77), Korruption oder mangelnde Bildung erscheinen müssen. Er kann den sich

74 Ders., Die dringendste Aufgabe unserer Bewegung, LW 4, S. 365

75 Vergl. Ders, Die Verfolger des Semstwos und die Hannibale des Liberalismus, LW 5, S. $25 \mathrm{ff}$.

76 Lenin, Was tun, LW 5, S. $385 \mathrm{f}, 394 \mathrm{f}, 436$

77 In dieser Auffassung ist auch Lenins These vom Entstehen einer Arbeiteraristokratie angelegt, mit der er das Phänomen des Opportunismus in der Sozialdemokratie im besonderen und Teilen der Arbeiterklasse in den Metropolen im allgemeinen zu erklären versucht. Nach seiner Auffassung wird die Arbeiteraristokratie mit Teilen des Extraprofits bestochen, den die imperialistischen Länder aus ihren Kolonien herauspressen, und so diese Schicht korrumpieren. Damit ist nicht nur die Frage des Entstehens von falschem Bewußtsein von den unmittelbaren gesellschaftlichen Verhältnissen getrennt und auf simple Bestechung reduziert, sondern impliziert eine derartige Auffassung auch eine Revision der Arbeitswertlehre, da der Lohn der Arbeiterklasse in den Metropolen nach Lenin in erster Linie nicht mehr der Geldausdruck des Werts der Ware Arbeitskraft ist, sondern ein politischer Lohn, der massenhaft und zu korruptiven Zwecken aus kolonialen Extraprofiten bezahit wird. 
innerhalb der russischen Arbeiterbewegung und der II. Internationale entfaltenden Opportunismus deshalb nicht als durch die ralative Unterentwickeltheit Rußlands bzw. die relative Prosperität des Weltmarktes und der entwickelten Länder bedingte Form falschen Bewußtseins bestimmen und so auch keine Schritte zur Zersetzung dieser Ideologie angeben.

Denn falsches Bewußtsein ist entweder Resultat unterentwickelter Produktions- und Klassenverhältnisse, oder sitzt den fetischisierten Erscheinungsformen der realen gesellschaftlichen Widersprüche unter favorablen konjunkturellen Bedingungen und der daraus resultierenden objektiven Beschränkung der Klassenkämpfe auf, und ist damit selbst wieder, wenn auch verkehrter, Ausdruck der tatsächlichen gesellschaftlichen Verhältnisse, wie sie an der Oberfläche erscheinen. Da Lenin keine Bestimmung der jeweiligen Bewußtseinsverfassungen aus den materiellen Verhältnissen vornehmen kann, reduziert sich das Bewußtseinsproblem der Arbeiterklasse für ihn auf reine Propagandatätigkeit. Die Arbeiter sind beständig der Propaganda der bürgerlichen Ideologie ausgesetzt, der sie von sich heraus nicht begegnen können. „Kann nun von einer selbständigen, von den Arbeitermassen im Verlauf ihrer Bewegung selbst ausgearbeiteten Ideologie keine Rede sein, so kann die Frage nur so stehen: bürgerliche oder sozialistische Ideologie" (78). Es gelte demnach für die sozialistische Fraktion der Intelligenz den Einfluß der bürgerlichen Fraktion und ihrer Ideologie zurückzudrängen, die im Gegensatz zur sozialistischen Ideologie den Vorteil hat, älter zu sein, vielseitiger entwickelt und über unvergleichlich mehr Mittel der Verarbeitung zu verfügen (79). „Darum bedeutet jede Herabminderung der sozialistischen Ideologie, jedes Abschwenken von ihr zugleich eine Stärkung der bürgerlichen Ideologie" (80). Da die spontane Entwicklung der Arbeiterbewegung nicht über den Rahmen gewerkschaftlichen Bewußtseins hinauskomme, führt sie nach Lenin letztenendes zu einer ,Unterordnung unter die bürgerliche Ideologie". Die Arbeiterklasse tendiere also von selbst zum Träger bürgerlicher Ideologie zu werden. „Von der Sozialdemokratie losgerissen, verflacht die Arbeiterbewegung und verfällt unweigerlich in Bürgerlichkeit: führt die Arbeiterklasse nur den ökonomischen Kampf, so verliert sie ihre politische Selbständigkeit, wird zum Anhängsel anderer Parteien und übt Verrat an dem großen Vermächtnis: ,Die Befreiung der Arbeiterklasse muß das Werk der Arbeiter selbst sein ${ }^{6 / 6}$ ( 81$)$.

Ganz abgesehen von der inneren Widersprüchlichkeit mit der Lenin zwar den Marx ${ }^{6}$ schen Hauptgedanken des Status der Internationalen Arbeiterassoziation wiederholt, aber im gleichen Satz betont, daß die Arbeiterklasse sich selbst gar nicht befreien kann, sondern dazu die in der Sozialdemokratie versammelte revolutionäre bürgerliche Intelligenz benötige, wird deutlich, daß Lenin den revolutionären Kampf nicht aus den materiellen Bedingungen erklärt. Er wird damit zu einer Sache der Wissenschaft, der höheren Moral, letztlich der erfolgreichen Propagandatätig.

78 Ders. Was Tun, LW 5, S. $395-96$

79 Ebd., S. 397

80 Ebd., S. 396

81 Ders, Die dringendsten Aufgaben unserer Bewegung, LW 4, S. 367 
keit, mit der Wissenschaft und Moral ins Volk getragen werden. Das sich für Lenin im Zusammenhang des Verhältnisses von Partei zu Klasse auftuende Problem ist damit in erster Linie ein technisches, nämlich das der effektivsten Verbreitung der sozialdemokratischen Ideen. Die Organisation von ökonomischen und vor allem politischen Enthüllungen mit Hilfe eines gesamtrussischen Zentralorgans (82) ist dabei die wesentliche Form, mit der Bewußtsein erweckt werden soll.

Dem entsprechend kommt Lenin auch zu einer völlig idealistischen Charakterisierung eines vorbildlichen Revolutionärs, indem er betont, „daß das Ideal eines Sozialdemokraten nicht der Sekretär einer Trade-Union, sonder der Volkstribun sein muß, der es versteht, auf alle Erscheinungen der Willkür und Unterdrückung zu reagieren, wo sie auch auftreten mögen, welche Schicht oder Klasse sie auch betreffen mögen, der es versteht, an allen diesen Erscheinungen das Gesamtbild der Polizeiwillkür und der kapitalistischen Ausbeutung zu zeigen, der es versteht, jede Kleinigkeit zu benutzen, um vor aller Welt seine sozialistische Überzeugung und seine demokratischen Forderungen darzulegen, um allen und jedermann die welthistorische Bedeutung des Befreiungskampfes des Proletariats klarzumachen" (83). Dementsprechend muß auch die Organisationsform der Partei diesen Kriterien genüge tragen, d.h. ein Maximum an Effizienz der Propagandatätigkeit zu sichern. Die Formen der kapitalistischen Rationalität, Arbeitsteilung, Spezialisierung und Hierarchisierung dienen als Vorbild für den Aufbau der revolutionären Organisation. Er geschieht von oben nach unten unter direkter ideologischer und praktischer Anleitung von Zentralorgan und Zentralkomitee, die alle Fäden in der Hand halten, und darauf achten, daß ,alle Räder und Rädchen der Parteimaschine“ (84) entsprechend ineinander greifen. Lenin kann zu einer derartigen Übernahme bürgerlicher Organisationsprinzipien für die revolutionäre Organisation, die eine hierarchische Zentralisierung durch die Parzellierung der Verantwortlichkeit der einzelnen Mitglieder der Organisation gegenüber bedingt (85), zum einen durch seine Aufgabenstellung für die Partei gelangen und zum anderen, durch sein, oben beschriebenes, mangelndes Verständnis des Formunterschieds von kapitalistischer und sozialisti. scher Vergesellschaftung und damit der Rationalität der Arbeit. Die sich aus den Bedingungen der Konspiration ergebenden Einschränkungen des demokratischen Prinzips sieht er vor allem in der Unmöglichkeit der vollständigen Publizität und der Wählbarkeit der Funktionäre (86). Aber dies empfindet er nur als geringen Mangel, da „strengste Konspiration, strengste Auslese der Mitglieder, Herausbildung von Berufsrevolutionären" (87) etwas "Größeres"s, als den „Demokratismus" sichern, „nämlich: das volle kameradschaftliche Vertrauen der Revolutionäre zueinander. (...) Sie haben keine Zeit, an spielerische Formen des Demokratismus zu

82 Ders, Womit beginnen?, LW 5, S. 10, siehe auch Was Tun, LW 5, S. 446

$83 \quad$ Ebd., S. $437^{2}$

84 Ders., Brief an einen Genossen über unsere organisatorischen Aufgaben, LW 6, S. 241

85 Ebd.,

86 Ders, Was Tun, LW 5, S. 495

87 Ebd., S. 498 
denken..., aber ihre Verantwortlichkeit empfinden sie sehr lebhaft, und zudem wissen sie aus Erfahrung, daß eine aus wirklichen Revolutionären bestehenide Organisation vor keinem Mittel zurückschrecken wird, wenn es gilt, sich von einem untauglichen Mitglied zu befreien ${ }^{66}(88)$. Lenin anerkennt die Möglichkeit, daß „eine straffe Zentralisation die Sache allzu leicht zugrunde richten kann, wenn der Zentralstelle zufällig ein mit sehr großen Machtbefugnissen ausgestat teter unfähiger Mensch angehört. Das ist natürlich möglich, aber das Mittel dagegen ist keineswegs Wählbarkeit und Dezentralisation ... Das Mittel gibt kein Statut, es kann nur gegeben werden durch, kameradschaftliche Einwirkung ... bis zum Sturz des völlig unfähigen Machtorgans" (89).

Lenins Organisationsplan entpuppt sich damit als klassische Form einer bürgerlichen Elitepartei, einer sich selbst regulierenden Führungsoligarchie. Dementsprechend fällt auch seine Einschätzung der emanzipatorischen Ansätze z. B. der englischen Gewerkschaftsbewegung aus, indem er den Verlust dieser Ansätze als historischen Fortschritt interpretiert. „Nicht nur wurden alle Fragen durch Abstimmung aller Mitglieder entschieden, sondern auch die Ämter wurden von allen Mitgliedern der Reihe nach ausgeübt. Es bedurfte einer langen geschichtlichen Erfahrung, damit die Arbeiter das sinnlose einer solchen Vorstellung von der Demokratie einsahen und erkannten, daß man einerseits Vertreterkörperschaften und andererseits Berufsfunktionäre braucht" ( 90$)$. Der Zusammenhang dieses Bürokratisierungsprozesses der Gewerkschaftsbewegung mit der von Lenin am gleichen Beispiel festgemachten Kritik am Trade-Unionismus als bürgerlicher Politik der Arbeiterbewegung, entgeht ihm in der Hitze der Polemik völlig, für ihn gilt: „Keine einzige revolutionäre Klasse kann ohne eine stabile und Kontinuität wahrende Führerorganisation Bestand haben“(91), und lobt deshalb auch die Entwicklung der deutschen Sozialdemokratie. „Das politische Denken der Deutschen ist schon entwickelt genug, sie haben genügend politische Erfahrung gesammelt, um zu verstehen, daß es ohne ein ,Dutzend' talentvoller (Talente kommen nicht zu Hunderten zur Welt), bewährter Führer ... in der heutigen Gesellschaft keinen beharrlichen Kampf einer Klasse geben kann“ (92).

Deutlich ist in dieser Konzeption die Amalgamierung der Marxismusrezeption der II. Internationale mit den Traditionen der russischen revolutionären Intelligentsia festzustellen, obwohl es zunächst an der Oberfläche der Zitate so erscheint, als ob sich Lenin nur voll im Rahmen der Ideologie der II. Internationale und namentlich der deutschen Sozialdemokratie und ihres führenden Theoretikers Kautsky bewegt, von dem Lenin wörtlich die prinzipiellen Passagen über das Ver-

Ebd.

89 Ders, Brief an einen Genossen ..., LW 6, S. 234 (Hervorhebung im Original)

90 Ders., Was Tun, LW 5, S. 499

91 Ebd., S. 480

92 Ebd., S. 478 
hältnis von Partei und Klasse übernimmt (93). Der Revisionismus der deutschen Sozialdemokratie basiert auf der besonderen Entwicklung des Kapitalismus in Deutschland und erfährt seine Ausprägung in der dynamischen Wachstumsperiode des Kapitalismus, die die materielle Wurzel für seine massenhafte und internationale Verbreitung darstellt. Spezifikum dieser Ideologie ist zum einen die direkte Verbindung der kleinbürgerlich-demokratischen und der proletarischen Opposition gegen das Bündnis zwischen absolutistischem Staat, Junkern und Bourgeoisie, die der Sozialdemokratie in dieser Funktion zwar eine historisch fortschrittliche Rolle zukommen läßt, aber gleichzeitig eine Abkehr von den Zielen der allgemeinen Emanzipation des Proletariats und der konkret zu diesen Zielen führenden Maßnahmen und Schritte bedeutet. Dieser Koalitionscharakter der Sozialdemokratie ist sowohl Ausdruck der politischen und ökonomischen Verhältnisse in Deutschland, d.h. der relativen Unterentwickeltheit und der Niederlage der 48er Revolution, wie er die Basis für eine Integrationsideologie abgibt, die die Kämpfe der Arbeiterklasse unter Führung der Partei im Rahmen der bürgerlichen Produktionsverhältnisse beschränken will, mit dem Ziel der schrittweisen Verbesserung der Lage der Arbeiterklasse und vor allem der Industrialisierung der Gesellschaft als direkter materieller Vorbereitung fur den Sozialismus.

Der andere Aspekt ist in der langen Prosperitätsphase der kapitalistischen Metropolen und namentlich Deutschlands von Mitte der 90er Jahre bis zum I. Weltkrieg zu sehen (94). Denn diese gesellschaftliche Entwicklung bot die materielle Basis dafür, daß sich Reformismus und Revisionismus der Sozialdemokratie als das beherrschende Element in der Arbeiterbewegung erhalten und entfalten konnten. Die unter diesen konjunkturellen Bedingungen mögliche Verbesserung der wirtschaftlichen und sozialen Lage der Arbeiterklasse durch gewerkschaftlichen Kampf und den beständig durch Wahlerfolge wachsenden politischen Einfluß der Sozialdemokratie, bedeuteten die objektive Beschränkung des Klassenkampfes auf Ziele, die innerhalb der bürgerlichen Produktionsverhältnisse zu erreichen waren, und das Entstehen einer dementsprechenden Ideologie, die dieser Taktik allgemeingültigen

93 Vgl. dazu z. B. die brühmte, von Lenin in ,Was Tun' direkt übernommene Passage aus Kautskys Artikel „Die Revission des Programms der Sozialdemokratie in Österreich" über das Hainfelder Programm der österreichischen Sozialdemokratie, in: Neue Zeit, Jg. 20, 1901/2, Bd. 1, S. 79/80, in dem die prinzipielle Bewußstseinsschranke der spontanen Arbeiterbewegung hervorgehoben ist, und von Kautsky gerechtfertigt wird, wie der Austromarxismus überhaupt in vielerlei Hinsicht dem deutschen Zentrismus entspricht und sogar praktisch (Hilferding) mit ihm Hand in Hand arbeitete.

94. Zur Theorie der langen Wellen vgl. die teilweisen kontroversen Beiträge von Parvus, Kautsky, Trotzki, Kondratieff und Mandel in dem Band: Die langen Wellen der Konjunktur, Beiträge zur marxistischen Konjunktur- und Krisentheorie, Berlin 1972, sowie besonders das 4. Kap. aus: Ernest Mandel, Der Spätkapitalismus, a.a.O., S. 103-37. Siehe außerdem das Referat von Mandel auf dem Kongreß in Tilburg im Sept. 1970, Geschichte des Kapitalismus und seine Bewegungsgesetze, in: Kapitalismus in den 70er Jahren, Frankfurt 1971, S. 7-32, und ders., Die Krise des Dollars und die Krise des Nachkriegskapitalismus, die Einführung zu: ders., Der Sturz des Dollars, Berlin 1973, S. $15-32$ 
Charakter verleihen will. Der direkte soziale Träger dieses Prozesses in den gewerkschaftlichen Massenorganisationen ist die dort entstehende Arbeiterbürokratie, als eine von der Klasse gesonderten, mit bestimmten Privilegien ausgestatteten Schicht, der die Vertretung der Interessen der Gesamtbewegung angetragen wurde und die in dem Maße, wie die Klassenkämpfe in beschränktem Rahmen verbleiben mußten, und trotz aller erzielten Erfolge nicht in sozialistischen Kampf umschlugen, sowohl ihre Positionen festigten, wie die sich daraus ergebenden materiellen und damit besonderen Interessen mit den allgemeinen Zielen der Arbeiterklasse verschmolzen. Die Bürokratie kann ihre Funktion, und damit ihre Privilegien aktuell und langfristig nur durch den Erhalt des gesellschaftlichen Status Quo sichern, d. h. es erwächst ein materielles Interesse am Erhalt dieses Status Quo, das sich in dem Maße verselbständigen kann, wie von Seiten der Arbeiterklasse nicht bewußt und ständig Gegenmaßnahmen getroffen werden, etwa durch die Festsetzung der Höhe der Gehälter, der Anwendung des Rotationsprinzips, der unmittelbaren und ständigen Möglichkeit der Kontrolle und Abwählbarkeit der Funktionäre etc. (95). Ohne diese Maßnahmen ist die Gefahr der Verkehrung des ursprünglichen Mittels in einen Selbstzweck angelegt und damit die Basis der Verfolgung einer im Interesse einer besonderen Schicht liegenden Politik unter der Vorgabe der Wahrnehmung allgemeiner Interessen gegeben ist.

Dieser vornehmlich für die Gewerkschaften charakteristische Prozeß fand natürlich in dem Maße in die Sozialdemokratie Eingang, wie sie sich zur Massenpartei entwickelte. Zusätzliches Charakłeristikum der Sozialdemokratie von Anbeginn war, im Gegensatz zu den Gewerkschaften, eine deutliche Dominanz des kleinbürgerlich intellektuellen Flügels in den Leitungsorganen der Partei, so daß die sich aus den Konstitutionsbedingungen der Sozialdemokratie ergebende Führungsrolle der Intelligenzfraktion, die ebenfalls in politischer Vertretung der Arbeiterklasse agierte, durch die entstehende Partei- und Gewerkschaftsbürokratie bestärkt wurde und sich ein Bündnis der verschiedenen Führungseliten der Arbeiterklasse ergab. Das gemeinsame dieser Fraktionen war trotz ihres unterschiedlichen sozialen Ursprungs, der ihr zur dauernden Legitimation ihrer Tätigkeit dienender prinzipieller praktischer und ideologischer Führungsanspruch gegenüber der Arbeiterklasse und der daraus resultierende substitutionalistische Charakter ihrer Politik (96).

Obwohl sich diese Widersprüchlichkeit und der Doppelcharakter der sozialdemokratischen Politik zu Beginn des Jahrhunderts noch in einem embryonalen. Zustand befand und sich erst in dem Maße verdeutlichte, wie sich die gesellschaftlichen Widersprïche zuspitzten und von der Sozialdemokratie eine Entscheidung abverlangten, die sie mit der Zustimmung zu den Kriegskrediten oder dem Regie-

95 Vergl. zum Komplex der Bürokratie in Arbeiterorganisationen und -staaten. Ernest Mandel, Über die Bürokratie, Mannheim o. J. (1970)

96 Vgl dazu: Bernd Rabehl, Wilfried Spohn, Ulf Wolter, Historische und politische Voraussetzungen der Kritik Mandelbaums am Sozialdemokratismus und am Leninismus, Nachwort zu: Kurt Mandelbaum, Sozialdemokratie und Leninismus, a.a.O., S. 79-119, in diesem Zusammenhang besonders Teil 1, Die klassenpolitischen Grundlagen des Sozialdemokratisnus, S. 79-105 
rungsantritt in der Weimarer Republik auch gab (97), bleibt dennoch die Frage offen, wieso sich Lenin die Grundlagen dieser revisionistischen Ideologie völlig zu eigen machte und nicht an den originären Marxismus anknüpfte. Weiter ist zu erklären, weshalb Lenin trotz der Kontinuität dieser Marxismusinterpretation zu teilweise gegensätzlichen taktisch-politischen Schlußfolgerungen gelangt, in welcher Beziehung also der Leninismus sowohl Kontinuität als auch Bruch mit den Sozialdemokratismus verkörpert.

Die Gründe für die Möglichkeit der übernahme des sozialdemokratischen Ideologie durch Lenin fußten offensichtlich auf den materiellen Verhältnissen Rußlands, wie oben in der Beschreibung der Entwicklungsgeschichte der russischen Intelligentsia nachzuweisen versucht wurde. Eine mit der bestehenden Gesellschaft unzufriedene, nicht in sie integrierte Intelligenz, die aber gleichzeitig von den unterdrückten Volksmassen getrennt war, mußte unter diesen Bedingungen im Namen und an Stelle dieses Volkes sprechen und handeln. Waren es zunächst die Bauern, so wurde die im Zuge der beginnenden Industrialisierung entstehende Arbeiterklasse als neue soziale Kraft entdeckt und führte zu einer Fraktionierung der Intelligentsia, zumal auf der anderen Seite die Agrarkrise und politische Borniertheit der Bauern den idealistischen Charakter der volkstümlerischen Idealisierung der Bauern und der Obscina verdeutlichten. Durch Lenins intensive Polemik mit den Narodniki erscheint es so, als habe er sich von deren Traditionen völlig gelöst. Aber seine Auseinandersetzungen mit ihnen berühren in erster Linie nur die Frage der Einschätzung der russischen Produktionsverhältnisse, ihrer Entwicklungsperspektiven und des Weges zum Sozialismus. Er kritisiert die Idee eines Agrarsozialismus, der gegenubber er die These der Notwendigkeit einer kapitalistischen Entwicklung Rußland als Vorbedingung für den Sozialismus betont. Dem entsprechend ist für ihn auch die Arbeiterklasse und nicht der Bauer sein primärer Adressat. Dagegen stehen Lenins Vorstellungen über die Rolle der Intelligenz und das Verhältnis von revolutionärer Organisation zu der zu führenden Klasse eindeutig noch in den Traditionen der russischen Intelligenz, die sich mit dem Volk verbunden fühlte, gegen dessen Elend rebellierte, aber noch keinen anderen Weg gehen konnte, als die Sache der Befreiung letztlich selbst in die Hand zu nehmen. Diese Grundhaltung finden wir auch bei Lenin, wenn er ausruft: „Gebt uns eine Organisation von Revolutionären, und wir werden Rußland aus den Angeln heben!“ (98). Entsprechend finden wir auch im Organisationsaufbau den deutlichen Einfluß der Narodniki. „Wir aber brauchen eine militärische Organisation von Agenten" (99). Seine Vorstellung von einem allmächtigen zentralen Gremium, Zentralkomitee und Zentralorgan, das alle Fäden in der Hand hat, und wo die Entscheidungen von oben nach unten laufen, lediglich Berichterstattung auf umgekehrtem Wege möglich ist, hatte bereits

97 Die Rolle der Sozialdemokratie im Krieg und in der Novemberrevolution, die Entwicklung ihrer Spaltung und ihres Niedergangs schildert: Richard Müller in seiner dreibändigen Geschichte der deutschen Revolution, Vom Kaiserreich zur Republik, Die Novemberrevolution, Der Bürgerkrieg in Deutschland, Berlin 1973 und 1974

98 Lenin, Was Tun, LW 5, S. 483

99 Ebd., S. 536 
N. P. Ogarjow 1862 fast wörtlich für die Untergrundorganisation ,Land und Freiheit" formuliert (100), sie waren auch die Prinzipien, nach denen die Narodna Wolja organisiert waren. So formuliert Lenin auch als Pflicht der Sozialdemokraten „eine ebenso gute, ja noch unvergleichlich bessere Organisation von Revolutionären zu schaffen, als die ,Semlja i Wolja' sie hatte. Im Gegenteil, diese Pflicht wird uns gerade durch diese Bewegung auferlegt, denn der spontane Kampf des Proletariats wird nicht zu einem wirklichen ,Klassenkampf" werden, solange dieser Kampf nicht von einer starken Organisation der Revolutionäre geleitet wird" (101). So sind die Verschwörerorganisationen der Narodniki konsequent auch Lenins „Vorbild“(102), ihr Fehler bestand seiner Meinung nach lediglich darin, ,daß sie sich auf eine Theorie stützten, die im Grunde genommen keine revolutionäre Theorie war" (103), weil sie sich nicht auf den proletarischen Klassenkampf orientierte, obwohl er gleichzeitig betont, daß die Narodniki eine richtige Bestimmung des nächsten politischen Kampfzieles vornehmen, nämlich den Sturz der Selbstherrschaft, den Lenin als ,,nächste politische Aufgabe der russischen Arbeiterpartei (104) sieht. Da er das Entstehen der Ideologie der Volkstümler ebensowenig aus den materiellen Verhältnissen und deren Beschränktheit erklären kann, wie das Entstehen revolutionären Klassenbewußtseins, ist es für in unproblematisch sowohl Organisationsform wie Taktik von den Narodniki zu übernehmen ohne dabei zu bemerken, daß sowohl die Idee eines Agrarsozialismus, des Sturzes der Selbstherrschaft durch die Aktion eines Verschwörerzirkels und die sich daraus ergebene bornierte und militärische Organisationsform in einem immanenten Zusammenhang stehen und Ausdruck der russischen Verhältnisse sind. Wenn Lenin durch seine Analyse des russischen Kapitalismus die politisch programmatischen Aussagen der Volkstümler durch die der Sozialdemokratie austauscht, aber sowohl Organisationskonzept, wie die politische Taktikbestimmung der Narodniki in wesentlichen Zügen beibehält, so ist dies sowohl der ideelle Ausdruck des rapiden relativen Wachstums der Arbeiterklasse in Rußland, wie auch der gleichzeitigen absoluten gesellschaftlichen Unterentwicklung. Es gelingt Lenin und der sozialdemokratischen Fraktion zwar sich von der utopischen Ideologie eines Agrarsozialismus loszusagen und im Proletariat die entscheidende Kraft des gesellschaftlichen Fortschritts und des Sozialismus zu sehen, ohne daß damit eine grundlegende Revision des bisherigen Verhältnisses der Intelligentsia zu der als fortschrittlich erachteten und zu führenden Klasse einherging, weil die Arbeiterklasse erst im Entstehen begriffen war und die ihr innewohnenden Potenzen noch nicht voll entfalten konnte. Dies ist die gesellschaftspolitische Grundlage, weshalb die revisionistische Marxismusinterpretation der II. Internationale unter den russischen Sozialdemokraten Fuß fassen konnte. Ihr

100 Vergl. S. V. Utechin, a.a.O., S. 116 f.

101 Lenin, Was Tun, LW 5, S. 492

102 Ebd., S. 491

103 Ebd., S. 492

104 Ders., Die đringendsten Aufgaben unserer Bewegung, LW 4, S. 365, vergl. auch, ders., Eine dringende Frage, LW 5, S. 216, und Was tun, LW 5, S. 421 
Kennzeichen war ebenfalls der prinzipielle Führungsanspruch der Parteiintelligenz und -bürokratie der Arbeiterklasse gegenüber, wenn auch aus teilweise unterschiedlichen gesellschaftlichen Bedingungen resultierend, ihre Gemeinsamkeit aber darin findend, daß die Arbeiterklasse - sei es aus Gründen der Unterentwickeltheit der kapitalistischen Produktions- und Klassenverhältnisse, also ihrer sozialen Schwäche, der politischen Entwicklung der Bourgeoisie und der Gesellschaft, oder denen konjunktureller Natur, wobei sich diese Faktoren nicht gegenseitig ausschließen, sondern vielmehr kombiniert, mit einer der jeweiligen gesellschaftlichen Entwicklung entsprechenden unterschiedlichen Gewichtung wirken - ihre Kämpfe nur in begrenztem Rahmen und mit einer sich daraus ergebenden beschränkten Zielsetzung führt. Die Ideologie der II. Internationale und der russischen Sozialdemokratie ist somit Produkt einer nicht-revolutionären Etappe der Entwicklung der Arbeiterbewegung. Sie erhalten ihre jeweiligen Ausprägungen, Nuancierungen und Verschiedenheiten durch die Ungleichheit der gesellschaftlichen Entwicklung in den imperialistischen Metropolen und dem unterentwickelten Rußland.

Gleichzeitig ist damit angedeutet, weshalb sich Elemente dieser Ideologien in der Sowjetunion nach dem Bürgerkrieg zum Dogma des Marxismus-Leninismus verdichten konnten, da wir in dieser Zeit eine klassenpolitische Konstellation sehen, die im nationalen und internationalen Maßstab von einem Rückgang der Klassenkämpfe geprägt ist und damit einhergehend konkret einen Verlust an Selbstätigkeit der Arbeiterklasse sowohl beim Aufbau des Sozialismus in der SU als auch beim Sturz des Kapitalismus bedeuten. Diese Einschränkung der Kampfziele und -formen der Arbeiterklasse gab die Basis für die Herausbildung und Festigung bürokratischer Stellvertreterherrschaft $a b$, zu deren Legitimation Elemente der substitutionalistischen ideologischen Traditionen benutzt wurden.

\section{Trotzkis Kritik am Lenin'schen Organisationsplan}

Wie bereits angedeutet, entwickelte sich die Lenin'sche Position nicht nur unter dem Einfluß und in der Auseinandersetzung mit den Traditionen der russischen Intelligentsia und der deutschen Sozialdemokratie. Lenin sah sich auch aus den Reihen der russischen und deutschen Sozialdemokraten mit Kritikern konfrontiert, die seine Theorie-, Taktik- und Organisationsauffassungen von einem egalitär marxistischen Standpunkt aus kritisierten und in ihren Auseinandersetzungen zumindest ansatzweise alternative Konzeptionen entwickelten (105).

Wir wollen im folgenden deshalb kurz eine grobe Skizzierung der wichtigsten Gedankengänge Trotzkis Kritik am leninistischen Organisationskonzept geben, die lediglich diesem beschränkten Zweck dienen soll und notwendig fragmentarisch bleiben muß, weil sie im Rahmen dieses Aufsatzes nicht in den Gesamtzusammen-

105 Uber das Verhältnis der Positionen des jungen Trotzki zu denen der linken Opposition in der SU zu dem Vorwort von Ulf Wolter zu. Ders. (Hrsg.), Programme und Dokumente der linken Opposition 1923-1928, Berlin 1975 
hang der theoretischen und politischen A.uffassungen dieses Theoretikers eingebettet werden kann (106). Sie erscheint uns notwendig, weil in diesen friihen Debatten Positionen formuliert und Fragestellungen aufgeworfen werden, die von unverminderter Aktualität sind, wie etwa die des Verhältnisses von Intelligenz und revolutionärer Organisation zur Arbeiterklasse, wobei in der aktuellen Diskussion dieser Probleme teilweise wieder an die früheren Auseinandersetzungen angeknüpft wird, die Fragestellungen im Lichte der historischen Erfahrungen der letzten 70 Jahre wieder aufgegriffen werden.

Der unmittelbare Anlaß für die Auseinandersetzung Trotzkis und Luxemburgs mit dem leninistischen Konzept war die auf dem II. Kongreß der SDAPR 1903 erfolgte Spaltung der russischen Sozialdemokratie in den bolschewistischen und menschewistischen Flügel. Der Parteitag, a]s Vereinigungskongreß einberufen, um die vielen lokalen Zirkel zu einer nationalen Organisation zu verbinden, konnte nach dem Austritt der Bundisten, der Organisation jüdischer Arbeiter, und der Fraktionierung diese ihm zugedachte Funktion nicht erfüllen. Die sich an scheinbar marginalen Punkten, wie dem $\S 1$ des Organisationsstatus festmachende Auseinandersetzung zwischen den Fraktionen war aber lediglich der organisationstechnische und damit verschleierte Ausdruck der unterschiedlichen Bestimmungen der politischen Aufgaben der russischen Sozialdemokratie und ihres Verhältnisses zur Arbeiterklasse. Die oben beschriebene allmähliche Trennung der sozialdemokratischen Fraktion von den ,legalen Marxisten war lediglich der erste Ausdruck dieser auch weiterhin stattfindenden Diskussion um die Entwicklungsperspektiven der russischen Gesellschaft und die daraus resultierende Taktikbestimmung der Sozialdemokratie. Die Position der sog. Ökonomisten, gegen die sich Lenins Polemik in erster Linie richtete, lehnte sich an die alte Position der Sozialdemokratie der neunziger Jahre an, als die revolutionäre Intelligenz ihre ersten Verbindungen zur Arbeiterklasse durch die Unterstützung ihrer unmittelbaren Kämpfe zu knüpfen begann, mit dem Ziel die organisierte Arbeiterklasse zur Unterstützung des Kampfes der liberalen Bourgeoisie gegen den Zarismus und für die Herstellung einer bürgerlichen Republik zu gewinnen. Zog die Fraktion der legalen Marxisten daraus den Schluß, daß es darauf ankomme, die Bourgeoisie direkt zu unterstützen und zu ihrem aktiven Parteigänger wurde, so lehnten die beiden sozialdemokratischen Fraktionen eine derartige Position ab, obwohl sie von der grundsätzlich gleichen Einschätzung ausgingen, daß in Rußland lediglich eine Phase der kapitalistischen Entwicklung gesellschaftlichen Fortschritts bringen könne. Angesichts der Rückständigkeit Rußlands gelte es, entsprechend dem klassischen sozialdemokratischen Etappenmodell der gesellschaftlichen Entwicklung, den westeuropäischen Weg nachzuholen und durch eine bürgerliche Revolution die Bedingungen zu schaffen, die eine rasche kapitalistische Entwicklung möglich machen, durch die sowohl in der Entwicklung der Produktivkräfte die materiellen Voraussetzungen für den Sozialismus geschaffen wer-

106 Neben dem Standardwerk, der Trotzi-Biographie Isaac Deutschers, empfichlt sich als einführende Lektüre in das Denken Trotzkis: Arno Münster, Trotzkis Theorie der ,Permanenten Revolution", Darmstadt 1973 
den, wie durch die quantitative Stärkung der Arbeiterklasse und die Agitationsmöglichkeiten der Sozialdemokratie unter den Bedingungen der Legalität die politischen Voraussetzungen., Die politische Führungsrolle in der anstehenden nächsten Etappe der Kämpfe falle daher der Bourgeoisie zu. Für die Sozialdemokratie müsse daher die Konsequenz sein, sich von dem direkten politischen Kampf fernzuhalten und sich im wesentlichen um die Organisation und Förderung des ökonomischen Kampfs der Arbeiterklasse zur Verbesserung seiner Lebenslage zu kümmern und so Einfluß und Verbindungen zu erhalten. Solange die bürgerliche Revolution bevorstehe, gelte es daher die Bourgeoisie in ihrem politischen Kampf gegen die Autokratie zu unterstützen. Erst im Rahmen kapitalistischer Verhältnisse sei eine eigenständige Klassenpolitik des Proletariats möglich, die sich dann gegen die Bourgeoisie wende. Bis dahin gelte es den Einfluß der Sozialdemokratie auf die Arbeiterklasse $\mathrm{zu}$ verstärken, was unter den gegebenen Bedingungen lediglich im ökonomischen Kampf möglich sei.

Grundsätzlich ging auch die Iskra-Fraktion um Lenin von der gleichen Einschätzung aus, daß nämlich Rußlands Weg zum Sozialismus nur über eine kapitalistische Entwicklungsphase führen könne. Zwar ging Lenin, wie wir gesehen haben, in seiner Klassenanalyse bereits von der Dominanz des Kapitalverhältnisses in Rußland aus, formulierte aber eine im Gegensatz zu dieser Analyse stehende politische Taktik nach der nicht der sozialistische Kampf auf der Tagesordnung stehe, sondern in Anlehnung an die Position der Volkstümler eine bürgerlich-demokratische Revolution und forderte so eine Beschränkung der Kampfziele der Sozialdemokratie auf politisch-demokratische Forderungen. Primat sei der Sturz des Zarismus, der mit allen Mitteln herbeigeführt werden müsse, um eine weitere kapitalistische Entwicklungsphase zu ermöglichen. Allerdings sah diese Fraktion die politische Schwäche der russischen Bourgeoisie und ihr Paktieren mit dem Zarismus. Sie kam von daher zu dem Schluß, daß die Bourgeoisie nicht der politische Träger der bürgerlich-demokratischen Revolution sein könne, hier müsse vielmehr die Arbeiterklasse in die Bresche springen und im Bündnis mit den Bauern die Revolution tragen, wobei es für Lenin klar war, daß es auf Grund der gesellschaftlichen Bedingungen kein ,Überspringen ${ }^{6}$ von seiner Meinung nach unumgänglichen Etappenfolgen der gesellschaftlichen Entwicklung geben könne und die Arbeiterklasse in politischer Selbstbeschränkung zum Träger der bürgerlichen Gesellschaft werden müsse. Ihren konkreten Ausdruck fand diese Position in der Formel der, demokratischen Diktatur der Arbeiter und Bauern'. Der Widerspruch zwischen dem nichtbürgerlichen Träger der Revolution und ihrem klassenpolitisch bürgerlichen Inhalt blieb unvermittelt und weist wieder auf Lenins mangelndes Verständnis sowohl der sich aus der Klassenlage des Proletariats ergebenden Interessen und Bewußtseinsformen wie des Formunterschiedes zwischen kapitalistischen und sozialistischen Formen der Vergesellschaftung der Arbeit als auch auf den substitutionalistischen Zug in seine Konzeption, wenn er im Namen des Proletariats eine Politik formuliert, die explizit eine Ausklammerung der unmittelbaren Interessen des Proletariats und eine völlige politische Selbstbeschränkung verlangt. 
Diesen unterschiedlichen Konzeptionen der russischen Revolution lagen den Debatten über die Organisationsfragen in der russischen Sozialdemokratie zugrunde. Während die Fraktion, die sich im wesentlichen auf die Förderung der ökonomischen Kämpfe des Proletariats beschränken wollte, entsprechend den Erfordernissen dieser Taktik den Rahmen der sozialdemokratischen Organisation möglichst weit spannen wollte, um besseren Einfluß auf die vielfältigen Kampfformen zu erlangen, legte die Fraktion um Lenin entsprechend ihrer Konzeption wert auf eine straff zentralisierte und schlagkräftige Organisation von Berufsrevolutionären. Ihr Primat der Politik, der Sturz der Selbstherrschaft und ihr Kampf gegen die zaristische Geheimpolizei mußten zu einer möglichst großen Einschränkung der Mitgliedschaft führen, um dem Sicherheitsbedürfnis der Organisation zu genügen und die Vertrauenswürdigkeit der einzelnen zu garantieren.

Diesen Zusammenhang von taktischen und organisatorischen Fragen berücksichtigend, ist Trotzkis Position einzuschätzen (107). Er betonte im Gegensatz zu den Menschewiki und Bolschewiki nicht nur die Zurïckgebliebenheit Rußlands Westeuropa gegenüber, sondern zugleich die historischen Besonderheiten der russischen Gesellschaft. Die Rückständigkeit Rußlands bei gleichzeitiger Einbeziehung in den kapitalistischen Weltmarkt mußte dazu führen, daß ein einfaches Nachholen der westeuropäischen Entwicklung nicht möglich sei. Die Einbeziehung des Zarismus in das Kalkül der entwickelten Bourgeoisstaaten und die ökonomische Abhängigkeit der russischen Bourgeoisie vom Zarismus, die zu einem reaktionären politischen Bündnis führte, sind die Kennzeichen der Besonderheiten der russischen Entwicklung und machen die russische Bourgeoisie unfähig zu einem Kampf gegen den Zarismus und zur Lösung der demokratischen Aufgaben, vor allem der Agrarreform. Andererseits hat aber die Geschichte der Bauernrevolutionen und der Bauernaufstände in Rußland selbst gezeigt, daß die Bauern als Klasse viel zu heterogen sind, um ihren Forderungen einen einheitlichen politischen Charakter zu verleihen. Von daher sei die zahlenmäßig kleine, aber stark konzentrierte Arbeiterklasse die einzige Kraft, die die Führung bei der Lösung der demokratischen und nationalen Aufgaben darstellen könne. Da sie in der Erkämpfung der bürgerlichen Freiheiten zugleich die Interessen der Mehrheit der bäuerlichen Bevölkerung vertritt, ist damit die Basis für ein Bündnis der Arbeiter mit den Bauern und damit eines Kräfteverhältnisses gegeben, das eine Revolution möglich mache. Die politische Führungsrolle, die der Arbeiterklasse in dieser Revolution zufällt, die Arbeiterregierung, kann allerdings auf Grund ihrer sich aus der Stellung im Produktionsprozeß ergebenden Interessenlage und der Dynamik der Klassenkämpfe nicht im Rahmen der bürgerlichen Produktionsverhältnisse bleiben und politische Selbstbeschränkung üben, sondern tendiert dazu, die bürgerlich demokratischen Aufgaben mit sozialistischen Mitteln zu lösen, die Revolution permanent zu setzen. Die Arbeiterregierung bildet demnach die politische Form der sozialen Emanzipation, wobei diese Emanzipation im nationalen Rahmen begonnen wird, ihren Abschluß aber erst im internationalen Maßstab

107 Schwierigkeiten exgeben sich aus der Tatsache, daß auf Grund der Tabuisierung Trotzkis bis heute noch keine Werkausgabe seiner Schriften existiert. 
finden kann.

Diese Analyse der Triebkräfte und Perspektiven der russischen Revolution machen Trotzki zu dem wesentlichen Vertreter des russischen Marxismus, der seine taktischen und organisatorischen Folgerungen aus einer fundierten und historisch als weitgehend richtig erwiesenen Einschätzung der russischen Verhältnisse ableiten konnte. Wenngleich die hier skizzierten Auffassungen von ihm in dieser Form auch erst vollständig 1905 als Teil seines Buches ,Rußland in der Revolution“" (108), der später unter dem Titel „Ergebnisse und Perspektiven“ (109) bekannt wurde, formuliert wurden, so ist doch offensichtlich, daß Trotzki bereits wesentliche Elemente dieser Position bereits vor der Revolution von 1905 vertrat. Sie finden ihren Niederschlag in taktischen organisatorischen Vorstellungen, die Trotzki Lenin und ab 1904 den Menschewiki gegenüber vertrat und ermöglichen ihm als einzigem sozialdemokratischen Führer einen entscheidenden Anteil in der Revolution von $1905 \mathrm{zu}$ nehmen.

Als den „Ursprung der Meinungsverschiedenheiten und Unstimmigkeiten, den Herd der inneren Unruhen, die unsere Partei bislang so sehr zerrissen haben" (110), sieht Trotzki die Frage nach dem Verfolgen einer eigenständigen Klassenpolitik des Proletariats in Rußland, die seiner Meinung nach in einen Prozeß der politischen Selbstbestimmung des Proletariats münden muß. Deshalb könne man sich nicht an den Erscheinungsformen dieser Frage festmachen, sondern muß zu ihrem Kern vordringen. „Um die organisatorischen Meinungsverschiedenheiten zu verstehen, muß man aus ihrem Rahmen treten - sonst erstickt man in scholastischen Wortgefechten" (111). Er leitet deshalb seine Kritik am Lenin"schen Organisationskonzept mit einer Kritik der ihm zugrunde liegenden Bestimmung der politischen Taktik ein. Es könne weder Aufgabe der Sozialdemokratie sein, das Proletariat als politisches Anhängsel der bürgerlichen Demokratie zu betrachten, in der Unterstützung der Bourgeoisie gegen den Zarismus aufzugehen und sich ansonsten lediglich der materiellen Besserstelluing des Proletariats zu widmen; noch könne es ihre Aufgabe sein, das Proletariat zum Vorkämpfer der bürgerlichen Gesellschaft zu machen und in seinen Forderungen zu politischen Selbstverzicht zu bewegen. „Die russische revolutionäre Bewegung muß sich, wenn sie als Arbeiterbewegung gesiegt hat, unverzüglich in den Prozeß der politischen Selbstbestimmung des Proletariats verwandeln sonst ist die russische Sozialdemokratie als solche ein Irrtum" (112). Um dieses Ziel zu erreichen, ist es seiner Meinung nach notwendig, das Proletariat schon jetzt in seinen Kämpfen auf diese Rolle vorzubereiten. Die vordringliche Aufgabe der

108 N. Trotzky, Rußland in der Revolution, Dresden 1909, vgl. auch den Nachdruck der zweiten, erweiterten Ausgabe von 1923, mit dem Titel, Die russische Revolution von 1905, Berlin 1972

109 L. Trotzki, Ergebnisse und Perspektiven, Frankfurt 1971

110 L. Trotzki, Unsere politischen Aufgaben, in: ders, Schriften zur revolutionären Organisation, Hamburg 1970, S. 12, siehe auch das informative Nachwort zur Position des frühen Trotzki in diesem Band von Hartmut Mehringer.

111 Ebd., S. 74

112 Ebd., S. 12 
Sozialdemokratie sei daher ,die Entwicklung des Klassen-Selbstbewußtseins und der Klassen-Selbsttätigkeit des Proletariats" (113). Weder der Ökonomismus, noch der Substitutionalismus der ,Politiker", wie er die Fraktion um Lenin auf Grund ihres Primats der Politik genannt hat, könne dieser Aufgabe gerecht werden, da beide Auffassungen, so unterschiedlich sie in ihren Konsequenzen auch sind, doch beide die Gemeinsamkeit haben, das zentrale taktische Problem der Sozialdemokratie, nämlich die Vermittlungsglieder zwischen den historischen Aufgaben der Arbeiterklasse und dem aktuellen Bewußtsein daruber, in keiner Weise zu lösen. Wies er schon 1903 darauf hin, daß der Leninsche Zentralismus ,nicht die Synthese der lokalen und allgemeinen Aufgaben, sondern schlicht die logische Antithese zur "Handwerkelei", eine formelle construction a contrario "(114) sei und damit methodisch gleich falsch vorgehe, so weist er weiterhin nachdrücklich auf den immanenten Zusammenhang von Reformismus und Sektierertum hin: „Das System der politischen Substitution geht ebenso wie das System der, ökonomischen' Vereinfachung bewußt oder unbewußt aus einem falschen, ,sophistischen' Verständnis des Verhältnisses der objektiven Interessen des Proletariats zu seinem Bewußtsein hervor" (115). Die Ökonomisten, die sich nur an der gegebenen Bewußtseinsverfassung der-Arbeiter festmachen und zum Fixpunkt ihrer Taktik machen, wie die Politiker, die lediglich allgemein politische Bestimmungen zur Grundlage ihrer Taktik erheben, betonen jeweils nur einen Aspekt der Totalität der realen Beziehungen, der aber in dieser Isolation zur Grundlage der Politik gemacht, zu falschen politischen Schritten führen muß, wohingegen Trotzki es gerade als Spezifikum der Sozialdemokratie ansieht, zwischen den sich aus der objektiven Klassenlage ergebenden Interessen und dem aktuellen Bewußtsein Vermittlungglieder aufzuzeigen, also ein Übergangsprogramm zu entwickeln, das diese Kluft zu überbrücken hilft. ,Für die taktische Weisheit der Partei liegt die ganze Aufgabe zwischen diesen beiden Ebenen, sie besteht in der Verkürzung und Erleichterung des Weges von der einen zur anderen" (116). Deshalb kommt er in Bezug auf die beiden streitenden Fraktionen zu dem Schluß: „Wenn die Ökonomisten auf diese Weise das Proletariat nicht führen, weil sie hinter ihm hertrotten, fuihren es auch die Politiker das Proletariat nicht, weil sie selbst seine Verpflichtungen zu erfülen suchen. Wenn die ökonomisten sich vor den kollossalen Aufgaben drücken, indem sie sich der bescheidenen Rolle zuwenden, am Schwanz der Geschichte zu marschieren, lösen die ,Politiker" die Frage dadurch, daß sie die Geschichte zu ihrem eigenen Schwanz machen $^{\text {"6 }}$ (117).

In diesem Zusammenhang wird die Zielrichtung von Trotzkis Kritik an Lenins Organisationskonzept offensichtlich. Sie richtete sich nicht gegen das Prinzip der zentralisierenden Zusammenfassung der lokalen Tätigkeiten an sich, sondern viel-

113 Ebd., S. 50

114 L. Trotzki, Rapport de la délégation sibérienne (1903), Paris 1970, S. 62

115 Ders., Unsere politischen Aufgaben, a.a.O., S. 70/71

116 Ebd., S. 71

117 Ebd., S. 73, vgl, auch: Zur Verteidigung der Partei, ebd,, S. 239 
mehr gegen bestimmte Formen des Zentralismus. Die Hauptkritik Trotzkis an der Lenin'schen Position betrifft daher die Frage der Selbsttätigkeit der Klasse, weil sowohl in Lenins taktischen wie organisatorischen Konsequenzen dieser Selbsttätigkeit enge Grenzen besetzt sind, während es nach Trotzki gerade die Hauptaufgabe sein müsse, diese anzuregen und zu fördern, um das russische Proletariat so zur Lösung der anstehenden politischen Aufgaben zu befähigen helfen. In Lenins Plan dagegen sieht Trotzki ein Hindernis bei der Entfaltung von politischem Bewußtsein und zudem die Gefahr, daß die Partei durch ihren unausgewiesenen Hegemonialanspruch der Klasse gegenüber und die daraus folgende strikte Absonderung eine derartig sektirerische Position einnimmt, daß das Proletariat der Partei in der entscheidenden Minute den Rücken kehren könne (118). Der formelle Zentralismus führe also nicht zu seinem erklärten Ziel, nämlich der Stärkung der Partei, sondern eher im Gegenteil zu der Gefahr der Trennung der Klasse von der Partei. Demgegenüber betont Trotzki, daß man ,die Garantie der Stabilität der Partei an ihrer Basis suchen (muß), im aktiven und selbsttätig handelnden Proletariat und nicht an ihrer organisatorischen Spitze“(119). Für ihn ist es deshalb vor allen organisatorischen Maßnahmen die primäre Aufgabe der Sozialdemokratie eine politische Taktik auszuarbeiten, die, anknüpfend an die aktuellen Kämpfe und das gegebene Bewußtseinsniveau, Kampfformen und Inhalte zum Gegenstand hat, in denen das Proletariat Erfahrungen sammeln und sich über seine Interessen klarwerden kann. Die Organisation ist dabei lediglich ein, wenn auch wichtiges, Mittel zur Erreichung dieses Zweckes. „Die organisatorischen Aufgaben ordnen sich deshalb für uns vollständig den Methoden unserer politischen Taktik unter, die Identifikation der organisatorischen Fragen der proletarischen Partei mit der technischen Frage des verbesserten Kampfes mit der Gendarmerie würde den völligen Bankerott bedeuten" (120).

Aber nicht nur in dieser Hinsicht entspreche das Leninsche Konzept nicht den Erfordernissen der Sozialdemokratie. „In der inneren Politik der Partei führen diese Methoden, wie wir noch sehen werden, dazu, daß die Parteiorganisation die Partei selbst, das $\mathrm{ZK}$ die Parteiorganisation und schließlich ein Diktator das ZK ersetzt" (121). Der hierarchische Aufbau und die fabrikmäßige Organisation der Partei, wie sie Lenin vorschlägt, sind ebenfalls keine, dem Entstehen von selbsttätig handelnden Sozialdemokraten förderlichen Bedingungen, sondern schaffen dagegen, Zwänge, Befehisgewalt und politische Monopole auf der einen Seite, Unterordnung, Disziplin und Abhängigkeiten auf der anderen Seite. „Wir sprechen von der unbedingten Notwendigkeit der Schaffung von Mitgliedern der Partei, von bewußten Sozialdemokraten, nicht aber von einfachen Teilarbeitern ... einer sozialdemokratischen Manufaktur" (122). Und an anderer Stelle heißt es: „Ebenso, wie es aber

118 Ebd., S. 87

119 L. Trotzki, Unsere Kriegs-Kampagne, Iskra Nr.62, 15. (28.) 3.1904, zitiert nach: Unsere politischen Aufgaben, a.a.O., S. 88

120 Ebd., S. 74

121 Ebd., S. 73

122 Ebd., S. 80/81 
unbegründet wäre, den Sozialismus mit dem Kapitalismus gleichzusetzen, würde es sinnlos sein, die Fabrik-Disziplin des Proletariats mit revolutionär-politischer Disziplin zu identifizieren. (...) Das Regime unserer Partei kann ebensowenig ein Kasernenregime sein, wie die Fabrik ihr Vergleich sein darf" (123).

\section{Modifikationen des leninistischen Organisationskonzeptes}

Zunächst ist festzuhalten, daß Lenin seinem eigenen Anspruch gegenüber, nämlich die Wissenschaft in den Dienst der Arbeiterklasse zu stellen, treu geblieben ist, wenn auch mit den oben beschriebenen widersprüchlichen Konsequenzen und sich immer bemühte, die aktuellen Tendenzen der Klassenkämpfe zur Grundlage seiner wissenschaftlichen und politischen Anschauungen zu machen. So war etwa die Revolution von 1905 nicht nur Ausgangspunkt für die Revision des Agrarprogramms und der strategischen Einschätzung der nächsten Kampfziele der Bolschewiki, sondern auch für Modifikationen in seinem Organisationskonzept, da er feststellen mußte, daß sich weite Teile der Bolschwiki äußerst sektiererisch gegenüber den entstehenden Arbeiterräten verhielten und entsprechend der bolschewistischen Auffassungen deren Unterordnung unter die Partei forderten (124).

Seine ersten Änderungen nahm Lenin allerdings bereits unter dem Eindruck der Auseinandersetzungen auf dem 2. Parteitag der SDAPR in Bezug auf die Rolle der Parteiintelligenz vor, da nach Lenins Analyse des Abstimmungsverhaltens der einzelnen Delegierten auf dem Kongreß, eine Spaltung in einen proletarisch-revolutionären (Bolschewiki) und einen intellektuell-opportunistischen Flügel (Menschewiki) stattfand (125). Da Lenin pauschal die Klassenlage der Intelligenz zur Grundlage seiner Bestimmung ihres Opportunismus machte, demgegenüber aber ,proletarisch $^{6}$ gleich ,revolutionär ${ }^{6}$ setzte (126), ohne daß er eine Änderung seiner bisherigen Erklärung der Genesis von revolutionärem Klassenbewußtsein vornahm, ist in seiner Konzeption der Avantgarde jetzt ein kompletter Zirkel beschrieben. Die Intelligenz. ist in seinen Augen nach wie vor Träger des wissenschaftlichen Sozialismus, aber zugleich auch des Opportunismus, während er der Arbeiterklasse ebenfalls nach wie vor die Möglichkeit der Gewinnung von revolutionärem Klassenbewußtsein ohne die Vermittlung der Intelligenz abspricht, das Proletariat aber gleichzeitig zum Garanten des revolutionären Charakters der Organisation machen will. Lenin schließt vom Opportunismus der Intelligenz, der durch ihre Klassen- und Lebenslage bedingt sei, auf den Opportunismus in Fragen der Taktik und Theorie (127), womit er auch das Aufkommen opportunistischer Tendenzen in der II. Internationale (Bernstein) zu

123 Ebd., S. 96

124 Vergl. dazu Oskar Anweiler, Die Rätebewegung in Rußland, 1905-21, Leiden 1958, Kap. II, Teil 4

125 Lenin, Ein Schritt vorwärts, zwei Schritte zurück, LW 7, S. 345

126 Ebd., S. 349, 392, $407 \mathrm{f}$.

127 Ebd., S. 266 f. 406 
erklären glaubt, während er die Disziplinierung der Arbeiter in der kapitalistischen Fabrik als Garantie für deren revolutionären Charakter sieht (128). Schien es auf den ersten Blick so, als habe Lenin stillschweigend eine Revision seiner Auffassungen über das Entstehen von Klassenbewußtsein vorgenommen, so wird jetzt deutlich, daß er lediglich eine willkürliche und sich selbst widersprechende Verkehrung des bisherigen Verhältnisses zwischen Intelligenz und Arbeiterklasse vornimmt. Er leitet seine Bestimmung nach wie vor nicht aus den materiellen Verhältnissen $a b$, kann von daher weder Kriterien für die Möglichkeit angeben, daß sich eine Intelligenzfraktion zur revolutionären Klasse bekennt, noch für das Entstehen des Opportunismus innerhalb der Arbeiterklasse selbst, sondern benutzt gerade im Gegenteil subjektive Kriterien und betont zudem noch die despotishe Seite der fabrikmäßigen Organisation der Arbeit als organisatorisch für die revolutionäre Partei vorbildlich. Eine weitere bedeutsame Modifikation des Organisationskonzeptes ergab sich aus den Erfahrungen der Revolution von 1905 und der sich in ihr zeigenden Gefahr, daß sich die Bolschewiki auf Grund ihres Sektierertums von der zu führenden Klasse lösen könnten. Obwohl Lenin nach wie vor den Kampf der Parteien, im Gegensatz zu den entstehenden Sowjets, als „,klarsten Ausdruck des politischen Kampfes der Klassen" (129) betrachtete und die Parteilosigkeit der Sowjets als „Ausdruck des bürgerlichen Charakters unserer Revolution“ (130) fehlinterpretierte, statt in ihnen die Klassenorganisationen des Proletariats zu sehen, ging es ihm doch um eine engere Verbindung der Partei zu den Volksmassen, die auch eine Modifikation der Organisationsstruktur zur Folge haben mußte. Die Verankerung des Prinzips des ,demokratischen Zentralismus" in der Organisation (131) soll dieses Ziel erreichen helfen. „Freiheit der Diskussion und Einheit der Aktion“ (132) werden als der Modus bestimmt, nach dem sich das „Organisationsprinzip der Partei überhaupt" (133), nämlich die Unterordnung der Minderheit unter die Mehrheit, durchsetzen soll. Lenin betonte zwar, indem er Plechanows Kritik auf dem 2. Parteitag nachträglich akzeptierte, daß er in ,Was Tun' in der Polemik gegen die Ökonomisten den Bogen überspannt habe (134), legt aber nach wie vor keine grundsätzliche Korrektur seiner bornierten Auffassungen über das Verhältnis von Partei und Klasse vor und beharrt weiter auf seiner Anschauung, daß das politische Klassenbewußtsein von außen in die Arbeiterklasse getragen werden müsse. Insofern ist die Verankerung des Prinzips des demokratischen Zentralismus ebenfalls keine prinzipielle Revision seiner Parteiauffassung, sondern stellt lediglich ein Mittel dar, mit dessen Hilfe es verhindert werden soll, daß sich die Partei von der Klasse entfremdet und damit ihren politischen Führungsaufgaben nicht mehr gerecht werden kann.

Die grundsätzliche Bestimmung dessen, was als leninistische Organisations-

128 Ebd., S. 395

129 Ders, Sozialistische Partei un;parteiloser Revolutionismus, LW 10, S. 65

130 Ebd.

131 Ders, Die Grundlagen der Organisation der Partei, LW 10, S. 156

132 Ders., Bericht über den Vereinigungsparteitag, LW 10, S. 384

133 Ders., Vorwort zur Broschüre ,Arbeiter über die Spaltung der Partei“ LW 9, S. 158

134 Ders, Vorwort zu dem Sammelband ,,12 Jahre", LW 13, S. 100 
konzeption bezeichnet wird (135), ist damit gegeben und es zeigt sich, daß zwar Modifikationen im Organisationsaufbau und im Verhältnis zur spontanen Arbeiterbewegung vorgenommen werden konnten, aber die grundsätzliche Bestimmung des Verhältnisses von Partei und Klasse nach wie vor, wenn auch in sich widersprïchlich, beibehalten wurde und so der verkehrte Ausdruck eines tatsächlichen Problems, nämlich der Ungleichzeitigkeit des Klassenbewußtseins, ist.

Weitere Nuancierungen ergeben sich im Gefolge der Auseinandersetzungen sowohl zwischen den Menschewiki und Bolschewiki, wie auch dem Fraktionskampf innerhalb der beiden Gruppierungen, $d$. h. den ,Otsowisten ${ }^{6}$ und den ,Ultimatisten in der bolschewistischen und den ,Liquidatoren ${ }^{6}$ in der menschewistischen Fraktion, wie auch der Kapitulation der II. Internationale vor den bürgerlichen Regierungen im I. Weltkrieg, ohne daß Lenin aber den prinzipiellen Begründungszusammenhang seiner Organisationskonzeption in Frage stellt und weiterhin nicht die Bedingungen für die Genesis von revolutionärem, wie auch opportunistischem Bewußtsein angeben kann. So bewegen sich Maßnahmen, wie etwa die Verhängung des Fraktionsverbotes 1921 innerhalb der KPR, das die Basis für die stalinistischen Parteisäuberungen abgab, vollständig im Rahmen der von Lenin erarbeiteten Organisationstheorie, deren absoluter Avantgardeanspruch auch zur theoretischen Rechtfertigung der Verteidigung der materiellen und politischen Privilegien der entstehenden Bürokratie in Staat und Gesellschaft der SU funktionalisiert werden konnte.

135 Ernest Mandel gibt in seinem Aufsatz: „Lenin und das Problem des proletarischen Klassenbewußtseins" in: Lenin. Revolution und Politik, Frankfurt 1970, S. 149-205 eine ausgezeichnete Darstellung seiner Organisationstheorie, der wir inhaltlich grundsätzlich zustimmen. Allerdings versucht Mandel dabei, seine Auffassungen im Wesentlichen als cine Interpretation der Leninschen Aussagen darzustellen, was offensichtlich nicht völlig korrekt ist. Mandel stellt sich damit in die Tradition der Linken Opposition, die ebenfalls versuchte, der stalinistischen Leninismusinterpretation ihre eigene entgegenzusetzen, ohne auf die tatsächlich vorhandenen Widersprüchlichkeiten des Leninismus einzugehen, die es den Id eologen der Bürokratic aber gerade erlaubte, sich auf die Leninschen Schriften zu berufen. Da die Opposition die Unantastbarkeit Lenins, wenn auch in einer anderen, teilweise zur offiziellen Version gegensätzlichen Interpretation, ebenso betonte, wie die stalinistische Fraktion, trug sie selbst zur Kanonisierung des Leninismus bei, die heute immer noch die herrschende Ideologie der KPen in den Übergangsgesellschaften und den kapitalistischen Ländern ist. Die 50-jährige Verballhornung des Marxismus, und die Politik, die im Namen des Marxismus-Leninismus gegenüber der Arbeiterklasse betrieben worden ist, verlangt aber von denen, die sich auf den revolutionären Marxismus berufen eine historisch-kritische Erörterung aller Aspekte, die zum Entstehen einer derartigen Ideologie geführt haben, um die Grundlage dafür zu legen, aus der Geschichte lernen zu können und zukünftig Wiederholungen alter Fehler zu vermeiden. Dazu gehört nicht nur wie es Mandel versucht, eine Darstellung der eigenen Position zu geben, die implizit eine radikale Kritik am Dogmatismus des Marxismus-Leninismus darstellt und seine Grundlagen in Frage stellt, sondern auch die Konsequenz, sein Verhältnis zu den Traditionen zu bestimmen, die heute noch wie ein Alp auf breiten Teilen der Arbeiterund Intellek tuellenbewegung lasten. 